\title{
Estrutura Competitiva, Produtividade Industrial e Liberalização Comercial no Brasil*
}

\author{
Pedro Cavalcanti Ferreira** \\ Osmani Teixeira de Carvalho Guillén ${ }^{* * *}$
}

Sumário: 1. Introdução; 2. O modelo; 3. Dados; 4. Estimação; 5. Resultados; 6. Conclusão.

Palavras-chave: produtividade; abertura comercial; mark-up.

Código JEL: D24.

This paper analyzes the behavior of the Brazilian manufacturing industry after the reforms implemented in the nineties. We examine the impact of trade liberalization on industry productivity and estimate the markup of different industrial sectors before and after trade liberalization. Estimates for markup showed a noncompetitive practices in most sectors. It was also observed jumps of productivity growht in the majority of the industrial sectors after the reduction of the trade restrictions. There is no significant indication of fall in the market power, which could point to the existence of other channels responsible for the productivity increase than competition from abroad.

O objetivo deste artigo é analisar o comportamento da indústria de transformação após as reformas implantadas na década de noventa. Verificamos se o processo de abertura gerou aumentos da produtividade média da indústria de transformação. Adicionalmente, estimamos o mark-up de diferentes setores industriais e testamos se este se modifica após a abertura comercial. Estimativas de mark-up revelam práticas não concorrenciais na grande maioria dos setores. Verifica-se também aumento da produtividade média e saltos de produtividade em grande parte dos setores industriais após a redução das barreiras comerciais. Não há indicação significativa de queda no poder de mercado após a abertura comercial, o

\footnotetext{
*Artigo recebido em fev. 2003 e aprovado em mar. 2004. Os autores agradecem os comentários de João Victor Issler e de dois pareceristas anônimos desta revista. As opiniões expressas neste trabalho não refletem necessariamente a visão do Banco Central do Brasil.

** EPGE/FGV-RJ. E-mail: ferreira@fgv.br. Este autor agradece financiamento do Ministério da Fazenda e do CNPq.

${ }^{* * *}$ Departamento de Estudos e Pesquisas, Banco Central do Brasil. E-mail: osmani.guillen@bcb.gov.br. Este autor agradece o financiamento da CAPES através do processo BEX0934/02-0.
} 
que poderia apontar para existência de outros canais responsáveis pelo aumento de produtividade.

\section{Introdução}

O objetivo desta pesquisa é analisar o comportamento da indústria de transformação perante a mudança de ambiente gerada pelas reformas comerciais implantadas no nosso país na década de noventa. A preocupação inicial é a de verificar se o processo de abertura gerou, como apontado pela literatura, aumento da produtividade média da indústria de transformação. Em segundo lugar, investiga-se a existência de um deslocamento do nível de produtividade causado unicamente por estas reformas. Em terceiro lugar, estimamos o mark-up de diferentes setores industriais e testamos se este se modifica após a abertura comercial. Por último, verificamos a importância de considerar a escala do setor industrial na estimação da produtividade dos diferentes setores industriais.

Para levar a frente esta análise utilizamos dados de produção, mão de obra e capital de dezesseis setores da indústria de transformação brasileira no período 1985-1997. O valor da participação da mão de obra no produto total utilizado é estimado para cada setor da indústria a partir de dados da matriz insumoproduto. Alternativamente, também utilizamos em nossas estimações valores da participação da mão de obra no produto frequentemente utilizados na literatura internacional.

O modelo econométrico empregado segue aquele proposto por Harrison (1994), onde é permitido especificar parâmetros associados com a produtividade média, saltos de produtividade relacionados somente com o processo de abertura comercial, o poder de mercado dos diferentes setores industriais, variações no markup causados pela nova política comercial e a escala de cada setor da indústria. Exercícios de contabilidade de crescimento que buscam analisar variações da produtividade industrial via de regra assumem concorrência perfeita e retornos constantes de escala. Entretanto, se o mercado for de fato não concorrencial antes da abertura comercial e se após esta as margens de lucro se reduzirem, os resultados neste exercício podem estar enviesados, como mostra Harrison (1994). Assim, ao levarmos em conta a estrutura concorrencial e a escala - de fato nós as estimamos - estamos adotando não só uma estrutura mais flexível mas também técnicas econométricas mais consistentes.

Referências básicas adicionais para o presente estudo são Hall (1988) e Domowitz et alii (1988). O primeiro artigo documenta a disparidade entre preço e custo marginal na indústria americana, encontrando que as variações cíclicas do 
fator mão-de-obra são menores que as variações do produto, o que revela comportamento de concorrência imperfeita. Em fases de alto crescimento as firmas produzem consideravelmente mais vendendo por um preço que excede o custo marginal dos insumos.

Domowitz et alii (1988) estudam a relevância da competição imperfeita em modelos com flutuações econômicas. Os autores propõem uma nova metodologia para a estimação de mark-ups do preço sobre o custo marginal. Para explicar o mark-up em alguns setores são importantes medidas como concentração industrial, competição com produtos importados e sindicalização dos setores estudados. Os autores mostram que as margens estimadas flutuam consideravelmente sobre o ciclo e que existem diferenças substanciais entre as flutuações das margens de indústrias de bens duráveis e não duráveis.

O artigo já citado de Harrison (1994) usa um painel de firmas do setor manufatureiro da Costa do Marfim, e mede as alterações das margens de lucro e a variação de produtividade que resultam das reformas comerciais de 1985. Este estudo também explora as diferenças de proteção entre os diversos setores e o fato de que podem ser encontradas estimativas enviesadas se não se leva em conta o impacto da liberalização comercial sobre a competição.

Tybout et alii (1991) e Tybout e Westbrook (1995) analisam os impactos da reforma comercial sobre as variações de desempenho da indústria das economias chilena e mexicana, respectivamente. Uma evidência interessante é que condições macroeconômicas adversas podem mascarar os efeitos positivos das reformas comerciais. Para a economia mexicana os autores encontram que os custos médios caem, especialmente para bens comercializados com o exterior.

Existem relativamente poucos artigos que estudam os efeitos da abertura comercial sobre a produtividade da indústria brasileira. Rossi e Ferreira (1999) analisam um painel da indústria de transformação brasileira, mostrando que o processo de abertura pode ser considerado um marco para a produtividade, enquanto que Carvalho (2000) analisa as causas do aumento de produtividade da indústria. Lisboa et alii (2002) investigam a influência da variação dos preços relativos, devida as reformas comerciais implantadas, sobre a adoção de novas tecnologias por parte das firmas, resultando em aumento de produtividade. Outras importantes referências a cerca dos impactos da abertura comercial brasileira sobre desempenho industrial são Ferreira e Rossi Jr. (2003), Hay (1997), Muendler (2001) e Moreira (1999), que entre outros tópicos estuda o comportamento dos mark-ups setoriais no período.

Este artigo inova em relação a literatura anterior por levar em conta a estrutura competitiva da indústria, já que não assumimos a priori competição perfeita. A 
flexibilidade do modelo nos permite também estimações assumindo ou não retornos constantes de escala, bem como verificar mudanças no padrão de competição industrial do país. Outra contribuição original do estudo é a construção de medidas de participação da mão de obra no produto. Hidalgo (2002) examina a relação existente entre o incremento da produtividade industrial e o processo de abertura comercial brasileiro utilizando arcabouço teórico semelhante ao nosso. Entre outros resultados, encontra um alto nível de mark-up para a indústria de transformação e aumento de produtividade após a liberalização comercial. Entretanto, este estudo investiga somente três sub-setores, além do comportamento da indústria de transformação como um todo e ignora mudanças de mark-up. Outra diferença marcante em relação ao nosso trabalho é que utiliza-se de forma ad hoc participações da mão de obra no produto iguais para todos os setores. Ao impor um valor para as participações (e um valor comum), ao invés de construí-las como no presente trabalho, pode-se estar incorrendo em erro de medida, o que viesaria os resultados.

O artigo encontra-se dividido em seis seções, incluindo esta introdução. A segunda seção apresenta o modelo teórico proposto. Na terceira seção descreve-se os dados a serem utilizados. A quarta descreve algumas técnicas de estimação para levar em conta problemas de escala e na quinta seção são apresentados os resultados das estimações dos diferentes modelos. A sexta seção conclui.

\section{O Modelo}

Seguindo a metodologia proposta em Hall (1988), Domowitz et alii (1988) e Harrison (1994), consideramos que a função de produção da firma $i$ na indústria $j$ no tempo $t$ é dado por:

$$
Y_{i j t}=A_{j t} f_{i t} G\left(L_{i j t}, K_{i j t}\right)
$$

onde:

$Y_{i j t}$ é o produto da firma $i$ na indústria $j$ no tempo $t$, que utiliza como insumos trabalho, $L_{i j t}$, e capital, $K_{i j t}$;

$A_{i j t}$ é um índice de progresso tecnológico neutro no sentido de Hicks, específico da indústria;

$f_{i t}$ é um parâmetro específico da firma que permite diferenças de tecnologia entre elas, e;

$G$ é uma função de classe $C^{2}$.

Diferenciando totalmente (1) e dividindo pelo produto da $i$-ésima firma $Y_{i j t}$, 


$$
\frac{d Y_{i j t}}{Y_{i j t}}=\frac{d A_{j t}}{A_{j t}}+\frac{d f_{i t}}{f_{i t}}+\frac{\partial Y_{i j t}}{\partial L_{i j t}} \frac{d L_{i j t}}{Y_{i j t}}+\frac{\partial Y_{i j t}}{\partial K_{i j t}} \frac{d K_{i j t}}{Y_{i j t}}
$$

os elementos $\partial Y_{i j t} / \partial L_{i j t}$ e $\partial Y_{i j t} / \partial K_{i j t}$ fazem parte da equação (2) porque consideramos que as empresas que detém poder de mercado não igualam o produto marginal ao preço do fator de produção. Se assumimos que as firmas do ambiente a ser modelado comportam-se segundo o modelo proposto por Cournot, o problema de maximização de lucro da $i$-ésima firma do setor $j$ deverá levar em conta o preço do produto do setor $j$, que é função da soma do produto de todas as firmas participantes deste setor, e o custo que a firma incorre no mercado de fatores. Em linguagem matemática, podemos escrever o problema de maximização de lucro da $i$-ésima firma como,

$$
\begin{aligned}
\underset{Y_{i j t}}{\operatorname{Maximizar} \prod_{i}\left(Y_{1 j t}, Y_{2 j t}, . ., Y_{n j t}\right)} & =P\left(Y_{j t}\right) Y_{i j t}-C_{i}\left(Y_{i j t}\right) \\
Y_{j t} & =\sum_{i=1}^{n} Y_{i j t} \\
C_{i}\left(Y_{i j t}\right) & =w_{j t} L_{i j t}+r_{j t} K_{i j t}
\end{aligned}
$$

onde:

os preços dos fatores de produção são representados por $w_{j t}$ (salário) e $r_{j t}$ (custo de aluguel do capital);

$L_{i j t}$ é a quantidade de mão de obra utilizada;

$K_{i j t}$ é a quantidade do fator capital utilizado;

$C_{i}\left(Y_{i j t}\right)$ é o custo da firma $i$ com insumos para produzir $Y_{i j t}$, e;

$P\left(Y_{j t}\right)$ é o preço de mercado associado ao produto $Y_{j t}$ (função demanda inversa).

Das condições de primeira ordem do problema da firma (3), podemos escrever,

$$
\frac{\partial Y_{i j t}}{\partial L_{i j t}}=\frac{w_{j t}}{P\left(Y_{j t}\right)} \frac{1}{\left[\frac{\partial P\left(Y_{j t}\right)}{\partial Y_{i j t}} \frac{Y_{i j t}}{P\left(Y_{j t}\right)}+1\right]}=\frac{w_{j t}}{P\left(Y_{j t}\right)} \frac{1}{\left[1+\frac{S_{i j t}}{e_{j t}}\right]}
$$

$\mathrm{e}$

$$
\frac{\partial Y_{i j t}}{\partial K_{i j t}}=\frac{r_{j t}}{P\left(Y_{j t}\right)} \frac{1}{\left[\frac{\partial P\left(Y_{j t}\right)}{\partial Y_{i j t}} \frac{Y_{i j t}}{P\left(Y_{j t}\right)}+1\right]}=\frac{r_{j t}}{P\left(Y_{j t}\right)} \frac{1}{\left[1+\frac{S_{i j t}}{e_{j t}}\right]}
$$

onde:

$S_{i j t}=Y_{i j t} / Y_{j t}$ é a participação da $i$-ésima firma no produto total do setor, e; 
$e_{j}$ é a elasticidade preço da demanda do setor $j\left(\left(\partial Y_{i j t} / \partial P\left(Y_{j t}\right)\right)\left(P\left(Y_{j t}\right) / Y_{j t}\right)\right)$. Obviamente, se $S_{i j t}=1$ temos o caso de monopólio e se $S_{i j t} \longrightarrow 0$, cada firma tem uma parcela infinitesimal do mercado e o equilibrio de Cournot aproxima-se do equilibrio competitivo. Fazendo

$$
\mu_{i j t}=\frac{1}{\left[1+\frac{S_{i j t}}{e_{j t}}\right]}
$$

onde $\mu_{i j t}$ pode ser interpretado como o fator de mark-up da i-ésima firma, e substituindo os resultados (4) e (5) em (2) obtemos,

$$
\frac{d Y_{i j t}}{Y_{i j t}}=\frac{d A_{j t}}{A_{j t}}+\frac{d f_{i t}}{f_{i t}}+\mu_{i j t}\left[\frac{w_{j t} L_{i j t}}{P\left(Y_{j t}\right) Y_{i j t}} \frac{d L_{i j t}}{L_{i j t}}+\frac{r_{j t} K_{i j t}}{P\left(Y_{j t}\right) Y_{i j t}} \frac{d K_{i j t}}{K_{i j t}}\right]
$$

Sabemos que $w_{j t} L_{i j t} / P\left(Y_{j t}\right) Y_{i j t}$ é a participação do fator trabalho no produto total, que será denotada de $\alpha_{L}$, e $r_{j t} K_{i j t} / P\left(Y_{j t}\right) Y_{i j t}$ é a participação do fator capital no produto total, que aqui será denotada de $\alpha_{K}$, temos: ${ }^{1}$

$$
\frac{d Y_{i j t}}{Y_{i j t}}=\frac{d A_{j t}}{A_{j t}}+\frac{d f_{i t}}{f_{i t}}+\mu_{i j t}\left[\alpha_{L} \frac{d L_{i j t}}{L_{i j t}}+\alpha_{K} \frac{d K_{i j t}}{K_{i j t}}\right]
$$

É relativamente simples mostrar que $\mu\left(\alpha_{L}+\alpha_{K}\right)$ é o fator de escala da tecnologia. Se utilizamos uma função de produção do tipo Cobb-Douglas $Y=A f L^{a} K^{b}$, com $a+b=\beta$, onde $\beta$ é o parâmetro de escala, podemos obter as seguintes relações:

$$
\frac{d Y}{d L} \frac{L}{Y}=a \text { e } \frac{d Y}{d K} \frac{K}{Y}=b \Rightarrow \frac{d Y}{d L} \frac{L}{Y}+\frac{d Y}{d K} \frac{K}{Y}=a+b=\beta
$$

mas das condições de primeira ordem do problema da firma (3), obtemos:

$$
\frac{d Y}{d L} \frac{L}{Y}+\frac{d Y}{d K} \frac{K}{Y}=\mu \alpha_{L}+\mu \alpha_{K}
$$

então temos $\mu \alpha_{L}+\mu \alpha_{K}=\beta$ ou $\alpha_{L}+\alpha_{K}=\beta / \mu$.

\footnotetext{
${ }^{1}$ Esta fórmula poderia ser derivada também a partir do modelo de Domowitz et alii (1988) que ao contrário de Harrison (1994) não trabalham competição de Cournot. Os primeiros autores chegam a uma fórmula exatamente igual à nossa equação $(8), \operatorname{com} \mu=1 /(1-\beta)$, onde $\beta$ é o índice de Lerner e, portanto, $(1-\beta)$ é igual a razão custo marginal/preço. A interpretação de $\mu$ como mark-up neste caso talvez seja mais imediata, entretanto, não haveria qualquer diferença nas equações posteriores, e portanto nos resultados, se utilizássemos esta derivação no lugar daquela que trabalhamos no texto, que consideramos mais completa e geral.
} 
Se consideramos uma tecnologia com retornos constantes de escala $(\beta=1)$, a participação dos fatores deverá somar $1 / \mu$, mas aqui consideramos o caso em que a soma das participações é igual a $\beta / \mu$, onde $\beta$ pode ser menor, igual ou maior que um. Subtraindo a taxa de variação do capital, $d K_{i j t} / K_{i j t}$, de cada lado da equação (8) e reescrevendo esta equação de maneira conveniente, com $\beta=\mu_{i j t}\left(\alpha_{L}+\alpha_{K}\right)$, obtemos,

$$
\frac{d Y_{i j t}}{Y_{i j t}}-\frac{d K_{i j t}}{K_{i j t}}=\frac{d A_{j t}}{A_{j t}}+\frac{d f_{i t}}{f_{i t}}+\mu_{i j t} \alpha_{L}\left[\frac{d L_{i j t}}{L_{i j t}}-\frac{d K_{i j t}}{K_{i j t}}\right]+[\beta-1]_{i j t} \frac{d K_{i j t}}{K_{i j t}}
$$

Fazendo $y=\operatorname{Ln}(Y / K)$ e $l=L n(L / K)$, podemos reescrever (9),

$$
d y_{i j t}=\frac{d A_{j t}}{A_{j t}}+\frac{d f_{i t}}{f_{i t}}+\mu_{i j t} \alpha_{L} d l_{i j t}+[\beta-1]_{i j t} \frac{d K_{i j t}}{K_{i j t}}
$$

Para entender o possível viés na estimação da medida de produtividade tradicional baseada em Solow, considere por um momento o termo $d f_{i t} / f_{i t}=0$. Sob retornos constantes de escala $(\beta=1)$ e concorrência perfeita $(\mu=1)$, pode-se verificar em (10) que a medida de Solow de produtividade, $d A / A$, será igual a medida de produtividade estimada $\left(d y_{i j t}{ }^{-} \alpha_{L} d l_{i j t}=d A_{j t} / A_{j t}\right)$. Entretanto, ainda sob retornos constantes de escala $(\beta=1)$ mas concorrência imperfeita $\left(\mu_{j}>1\right)$, obtemos de (10), $d y_{i j t^{-}} \alpha_{L} d l_{i j t}=(\mu-1) \alpha_{L} d l_{i j t}+d A_{j t} / A_{j t}$. Neste caso variações em $l$ implicam em uma estimação viesada da medida de Solow de produtividade, $d A / A$. Finalmente, se $\beta \neq 1$ teremos mais um termo $-[\beta-1]_{i j t} d K_{i j t} / K_{i j t}-$ enviesando a estimativa de produtividade tradicional.

\section{Dados}

Para investigar os efeitos gerados nos diversos setores da indústria pela queda de barreiras e reforma tarifária utilizamos um painel com observações do período de 1985 a 1997 de dezesseis setores da indústria de transformação brasileira. ${ }^{2}$ Em seguida descreveremos brevemente os dados utilizados.

\footnotetext{
${ }^{2}$ Quais sejam: Transformação de Produtos Minerais Não-Metálicos, Metalurgia, Mecânica, Material Elétrico e de Comunicações, Material de Transportes, Papel e Papelão, Borracha, Química, Produtos Farmacêuticos e Veterinários, Perfumaria, Sabões e Velas, Produtos de Materiais Plásticos, Têxtil, Vestuário, Calçados e Artefatos de Tecidos, Alimentícia, Bebidas e Fumo.
} 


\section{- Produção}

Da Pesquisa Industrial Mensal - Produção Física (PIM-PF) extraímos dados agregados de produção de cada setor. Dos dados pode ser verificado o crescimento da produção a partir de 1991 dos diversos setores, com exceção da indústria Têxtil e a de Vestuário, Calçado e Artefatos de Tecidos.

- Mão de obra

Da Pesquisa Industrial Mensal - Dados Gerais (PIM-DG) obtivemos o pessoal ocupado na produção e o número de horas trabalhadas na produção. É notória a queda destas séries em todos os setores estudados e cabe observar que as indústrias Têxtil e de Vestuário, Calçado e Artefatos de Tecidos apresentam a maior taxa de decaimento para o período estudado. São utilizados dados de pessoal e total de horas empregadas na produção porque estes dados são menos sensíveis ao processo de terceirização observado neste período o que não levaria a uma superestimação da produtividade, ou pelo menos minimizaria o problema.

\section{- Capital}

Tabulações especiais da Pesquisa Industrial Anual podem nos fornecer informação sobre ativos imobilizados (KP), compras de máquinas e equipamentos (MT) e investimentos (INV). As duas últimas podem ser utilizadas como proxy de investimentos (para a construção de séries de capital) e a primeira pode ser utilizada diretamente como proxy do estoque de capital.

A série MT é a razão entre o total de compras de máquinas e equipamentos feitas pelo setor e a receita líquida de vendas (RLV) do setor. O valor total da compra de máquinas se refere ao valor total dos gastos em máquinas nacionais e estrangeiras. Já a RLV corresponde à receita bruta deduzida dos impostos incidentes sobre as vendas, das vendas canceladas, descontos e fretes pagos a terceiros para a entrega dos produtos, quando considerados nas vendas brutas.

A série INV é a razão entre as aquisições feitas pelo setor em questão e a RLV. As aquisições compreendem os recursos aplicados em bens associados comumente aos chamados "custos fixos de produção" de permanência duradoura e os gastos necessários para colocar esses bens em local e condições de uso no processo operacional da empresa, incluindo o custo de melhoramentos e benfeitorias que tenham aumentado a vida útil dos bens. A série exclui os encargos financeiros decorrentes de financiamentos. 
A construção de séries de capital a partir destas duas séries (INV e MT) requer inicialmente a multiplicação da variável em questão por RLV, para se obter uma série de investimento usual, I. Em seguida, aplica-se o método do estoque perpétuo ("Perpetual Inventory Method"). Basicamente, utiliza-se recursivamente a lei do movimento do capital:

$$
K_{j t+1}=I_{l t}+(1-\delta) K_{j t}
$$

onde $K_{j t}$ é o estoque de capital em no período $t$ do setor $j$, e a $\delta$ taxa de depreciação. Obviamente necessita-se de uma estimação do estoque de capital inicial e da taxa de depreciação. Em Ferreira et alii (2000) mostrouse ser de pouco relevância da escolha de uma taxa de depreciação entre $3 \%$ e $12 \%$. Por isso, será computado aqui somente a série de capital que utiliza a taxa de $9 \%$ ao ano, seguindo aquele artigo. O valor inicial do estoque de capital $K_{0}$, será calculado segundo a técnica de Young (1995) e de Hall e Jones (1999), pela aproximação $K_{0}=I_{0} /\left(g_{j}+\delta\right)$, onde $g_{j}$ é a taxa de crescimento do investimento no período. O problema óbvio aqui é a pequena extensão da série, o que faz com que imprecisões no cálculo do capital inicial se propaguem para toda série de capital.

Como medida de capital utilizamos estimativas do "capital efetivamente utilizado" que é obtido mediante o produto da medida de utilização da capacidade em cada setor, calculada pelo IBRE-EPGE, pelo estoque de capital de cada setor, $K_{j t}$. Este procedimento minimiza a influência de flutuações cíclicas sobre a medida de produtividade. Os dados foram deflacionados utilizando séries do IPA-OG. Como resultado final, passamos a dispor de 3 séries de capital: as construídas a partir de MT e INV e a que usa KP diretamente. Como os resultados pouco diferiram entre si, reportaremos aqueles obtidos com a série de capital construida a partir da variável $\mathrm{MT}^{3}$

- Participação da mão de obra no produto total

Propomos uma metodologia onde se busca calcular diretamente a participação da mão de obra em cada setor da indústria de transformação. Para isto utilizamos dados de remunerações totais, rendimentos de autônomos e valor adicionado a custo fatores disponíveis na matriz insumo-produto, disponibilizada pelo IBGE para o ano 1985 e para o período 1990-1996. Para

\footnotetext{
${ }^{3}$ Entre outras razões porque esta foi a série utilizada em Rossi e Ferreira (1999) e assim pode-se comparar resultados.
} 
cada ano em que existe a informação, calcula-se a participação da mão-deobra em cada setor como a razão da soma das remunerações totais mais rendimentos de autônomos e o valor adicionado a custo fatores de cada setor. A média aritmética dos resultados anuais obtidos para cada setor, cujos valores encontram-se na tabela 1 a seguir, será a participação do trabalho no produto.

Para testar a robustez dos valores descritos na tabela 1 , consideramos valores para $\alpha_{L}$ iguais a 0,50 e 0,55 , valores próximos das estimativas do IBGE para o Brasil. Testaremos também estimativas utilizadas freqüentemente na literatura internacional, em que a participação do capital no produto total é igual a um terço e a participação do trabalho no produto total é igual a dois terços. Assumimos nestes três casos que a participação do trabalho no produto total de cada setor, $\alpha_{L}$, é a mesma para todos os setores.

Este procedimento, entretanto, possui problemas. Ao assumirmos que a participação do trabalho no produto é a mesma em todos setores estamos desconsiderando diferenças tecnológicas e distintas intensidades relativas dos fatores. Este foi o procedimento utilizado por Hidalgo (2002). Entretanto, como pode-se ver pela tabela 1, há grande variabilidade deste parâmetro entre os setores, e a deconsideração deste fato implica em erro de mensuração e nos usuais problemas econométricos associados a isto.

Na tabela 1 pode ser observado que as aproximações usuais da participação do trabalho no produto total agregado $\left(\alpha_{L}\right.$ iguais a $0,50,0,55$ e 0,65$)$, tendem a superestimar a participação do trabalho na maioria dos setores, o que pode ter grande influência nos resultados finais das estimações de produtividade e de comportamento não concorrencial. ${ }^{4}$ Pode ser notado também, como esperado, que setores mais intensivos em capital como Transformação de Produtos Minerais Não-Metálicos, Material Elétrico e de Comunicações, Material de Transportes, Borracha, Química e Produtos Farmacêuticos possuem uma baixa participação da mão de obra no produto total.

\footnotetext{
${ }^{4}$ Obviamente este trabalho não é o primeiro a apontar que medidas da participação da mão-deobra no produto industrial são em geral inferiores que medidas agregadas. Isto é esperado quando se leva em conta que o setor industrial é, comparado com o setor de serviços e com a agricultura, relativamente intenso em capital. Nossa contribuição maior aqui é construir medidas específicas para cada setor, como ressaltado anteriormente. Entretanto, como citado acima, alguns trabalhos anteriores utilizam a mesma participação para todos os setores, sendo esta próxima da medida calculada para o país como um todo.
} 
Tabela 1

Participação da mão de obra calculada a partir da matriz insumo-produto

\begin{tabular}{lc}
\hline \multicolumn{1}{c}{ Setores Industriais } & Participação da mão de obra \\
\hline Transformação de Produtos Minerais Não-Metálicos & 0,315 \\
Metalurgia & 0,409 \\
Mecânica & 0,491 \\
Material Elétrico e de Comunicações & 0,318 \\
Material de Transporte & 0,296 \\
Papel e Papelão & 0,554 \\
Borracha & 0,269 \\
Química & 0,218 \\
Produtos Farmacêuticos e Veterinários & 0,338 \\
Perfumaria, Sabões e Velas & 0,492 \\
Produtos de Materiais Plásticos & 0,367 \\
Têxtil & 0,296 \\
Vestuário, Calçados e Artefatos de Tecidos & 0,734 \\
Alimentícia & 0,335 \\
Bebidas & 0,425 \\
Fumo & 0,492 \\
\hline
\end{tabular}

Um problema potencial do artigo é que não há dados disponíveis para insumos intermediários. Neste sentido nossas estimações se distanciam daquelas de Harrison (1994). Este seria um problema menor se nossa série de produto fosse uma série de valor adicionado, mas esta também não está disponível na PIM e há somente uma proxy na PIA, a série Valor da Transformação Industrial, de qualidade questionável. Isto porque esta série não exclui várias despesas (por exemplo, gastos com publicidade, aluguéis, transportes, comunicação e serviços em geral) e sendo uma série anual sofre efeito maior da inflação pré 1994. Assim, trabalhamos com a hipótese forte que variações do valor da produção estão correlacionadas com variações do valor agregado. A violação desta hipótese implicaria em provável viés de nossas estimações. Em Ferreira e Rossi Jr. (2003) há uma discussão mais longa desta questão. Estes autores mostram que estimações da TFP e os resultados de regressões de taxa efetiva de proteção na TFP não mudam muito se a série de produção for substituida pela de Valor da Transformação Industrial.

\section{Estimação}

\subsection{Modelo com retornos constantes de escala}

A partir da equação (9), iremos assumir, em primeiro lugar, retornos constantes de escala $(\beta=1)$, de forma que obtemos, 


$$
\frac{d Y_{i j t}}{Y_{i j t}}-\frac{d K_{i j t}}{K_{i j t}}=\mu_{i j} \alpha_{L}\left[\frac{d L_{i j t}}{L_{i j t}}-\frac{d K_{i j t}}{K_{i j t}}\right]+\frac{d A_{j t}}{A_{j t}}+\frac{d f_{i t}}{f_{i t}}
$$

Chamando de $z$ o logaritmo da razão entre o produto e o fator capital, o incremento infinitesimal desta nova variável pode ser representado por $d z_{i j t}=$ $\left[d Y_{i j t} / Y_{i j t}-d K_{i j t} / K_{i j t}\right]$, enquanto que se $x$ representa o logaritmo da razão entre os insumos trabalho e capital, seu incremento infinitesimal será $d x_{i j t}=\left[d L_{i j t} / L_{i j t}\right.$ $\left.-d K_{i j t} / K_{i j t}\right]$, a equação (12) poderá ser expressa como:

$$
d z_{i j t}=\mu_{i j} \alpha_{L} d x_{i j t}+\frac{d A_{j t}}{A_{j t}}+\frac{d f_{i t}}{f_{i t}}
$$

O termo da produtividade, $d A_{j t} / A_{j t}$, pode ser visto como uma média do crescimento de produtividade da indústria $j$, que pode ser capturado por um coeficiente $C_{0 j}$.

Como utilizamos dados agregados por setores industriais, o fator de mark-up será $\mu_{j t}=\mu_{i j t}$ para todo $i$. Para estimar o de mark-up de cada setor, substituímos o termo que representa o mark-up da indústria, $\mu_{j}$, por um coeficiente $C_{1 j}$ que captará a diferença entre o preço e o custo marginal para o setor $j$.

Para verificar se houve mudança de comportamento das firmas, como por exemplo redução da margem de lucro, com a implantação do processo de abertura, incluímos um coeficiente $C_{2 j}$ que estará associado a uma variável dummy que marcará o ponto do tempo em que as medidas foram implantadas. A variável dummy de implantação da abertura comercial, aqui chamada de $D$, é igual a zero no período 1985-1990 e igual a um no período restante, quando assumimos que grande parte das medidas de redução e remoção de barreiras comerciais já estavam implementadas.

Para captar possíveis deslocamentos de produtividade induzidos nos diferentes setores pela reforma comercial incluímos um coeficiente $C_{3 j}$ que estará associado a dummy $D$. O termo específico da firma, $d f_{i t} / f_{i t}$, pode ser decomposto em um termo específico de planta, $g_{i}$, e um termo aleatório, $u_{i t}$. Neste trabalho utilizamos dados agregados de setores industriais, logo o termo específico de planta não aparece $\left(g_{i}=0\right)$. Com as modificações introduzidas em (13), chegamos ao modelo a ser estimado,

$$
d z_{i j t}=C_{o j}+C_{1 j} \alpha_{L} d x_{i j t}+C_{2 j} D \alpha_{L} d x_{i j t}+C_{3 j} D+u_{i t}
$$

Esperamos que, se a redução de barreiras não-comerciais e a redução de tarifas implicam em crescimento da produtividade média da indústria no período 
estimado, o coeficiente $C_{o}$ deva ser positivo. Se existe comportamento não competitivo, o coeficiente que mede poder de mercado, $C_{1}$, indicará o mark-up praticado no setor. A indicação de validade do poder de mercado pode ser verificada testando para quais setores o coeficiente estimado é significativamente diferente de um. Para isto utilizamos um teste de hipótese linear fazendo $\widehat{\Theta}_{i}=1$ como hipótese nula. ${ }^{5}$ Esperamos que a estimativa do coeficiente $C_{2}$ seja negativa refletindo um comportamento mais competitivo, isto é, queda do mark-up praticado em virtude da maior exposição a competição internacional. Finalmente, se as reformas introduzidas implicam em um salto de produtividade dos diferentes setores, o coeficiente $C_{3}$ deve ser positivo.

\subsection{Modelo sem restrição sobre a economia de escala}

A partir da equação (9), utilizamos a mesma metodologia aplicada na subseção 4.1, chamamos de $z$ o logaritmo da razão entre o produto e o fator capital, o incremento infinitesimal que é igual a diferença desta nova variável pode ser representado por $d z_{i j t}=\left[d Y_{i j t} / Y_{i j t}-d K_{i j t} / K_{i j t}\right]$, enquanto que se $x$ representa o logaritmo da razão entre os insumos trabalho e capital, seu incremento infinitesimal será $d x_{i j t}=\left[d L_{i j t} / L_{i j t}-d K_{i j t} / K_{i j t}\right]$ e a taxa de variação do capital $d k_{i j t}=d K_{i j t} / K_{i j t}$ a equação (12) será,

$$
d z_{i j t}=\mu_{j} \alpha_{L} d x_{i j t}+[\beta-1]_{i j t} d k_{i j t}+\frac{d A_{j t}}{A_{j t}}+\frac{d f_{i t}}{f_{i t}}
$$

aproveitando a mesma notação da subseção 4.2 e chamando de $C_{4 j}=\beta-1$ o coeficiente que capta a escala do setor, chegamos ao modelo a ser estimado,

$$
d z_{i j t}=C_{o j}+C_{1 j} \alpha_{L} d x_{i j t}+C_{2 j} D \alpha_{L} d x_{i j t}+C_{3 j} D+C_{4 j} d k_{i j t}+u_{i t}
$$

\section{Resultados}

\subsection{Modelo com retornos constantes de escala}

O modelo sugerido na subseção 4.1 (14) pode ser estimado de duas maneiras diferentes; em primeiro lugar, podemos considerar que o processo de abertura

$5 \frac{(R \hat{\Theta}-r),\left[R\left(X^{\prime} X\right)^{-1} R^{\prime}\right](R \widehat{\Theta}-r) / q}{e^{\prime} e /(n-k)} \backsim F(q, n-k)$, onde a hipótese linear é $R \Theta=r . \quad R$ é uma matriz $q \times k$ onde especificamos as hipóteses a serem testadas, e $r$ é um vetor de dimensão $q$ ao que se atribui o valor a ser testado. O procedimento do teste é rejeitar a hipótese se valor calculado de $\mathrm{F}$ ultrapassa o valor crítico. 
gera um salto de produtividade igual para todos os setores industriais, o que é equivalente a impor a restrição de igualdade para os coeficientes que medem este deslocamento $\left(C_{3 j}=C_{3}\right.$, para todo $\left.j\right)$; em segundo lugar, consideramos que este coeficiente é diferente para cada setor da indústria.

\subsection{Modelo com deslocamento de produtividade igual para todos os setores}

O modelo (14) foi estimado por mínimos quadrados ordinários e variáveis instrumentais. ${ }^{6}$ O teste de Hausman, realizado equação por equação, é utilizado neste exercício para verificar se as estimativas por mínimos quadrados ordinários e variáveis instrumentais diferem significativamente. O resultado do teste, tabela A.1 do apêndice, não rejeita a hipótese de igualdade de coeficientes em todas as equações estimadas, e a maioria dos coeficientes estimados pelos dois métodos apresentam um comportamento bastante semelhante. Diante dos resultados obtidos, usaremos a estimação por mínimos quadrados ordinários para análise do comportamento dos diferentes setores. Nesta primeira estimação impusemos a restrição de igualdade do coeficiente que mede o salto de produtividade, o que equivale a dizer que a produtividade comporta-se da mesma maneira para todos os setores após a abertura. Como estamos utilizando dados agregados por setores, a constante específica de planta é considerada igual a zero.

Os resultados das estimações do modelo com participações do trabalho no produto total, $\alpha_{L}$, calculadas a partir da matriz insumo-produto, encontram-se descritos na tabela 2 .

O coeficiente estimado de crescimento da produtividade média, $C_{0}$, é significativo em treze das dezesseis industrias analisadas. As exceções são as indústrias de Material de Transporte, Papel e Papelão e Produtos Farmacêuticos e Veterinários. Como se poderia esperar os coeficientes estimados são todos positivos, mas há uma relativa dispersão nestes valores indicando diferentes padrões de produtividade por setor: a razão entre o maior e o menor coeficientes estimados (da indústria de Fumo e da de Transformação de Minerais Não-Metálicos, respectivamente) é de quase $90 \%{ }^{7}$

\footnotetext{
${ }^{6}$ Os intrumentos utilizados foram a taxa de câmbio real, horas trabalhadas, razão capital horas trabalhadas, razão capital mão-de-obra empregada e respectivas defasagens. Embora a escolha de instrumentos adequados seja um problema recorrente a todas estimações deste tipo, parece-nos que a utilização das variáveis independentes defasadas não envolve sérios problemas. Isto porque estão correlacionadas com as variáveis dependentes contemporâneas mas, com toda probabilidade, não com o resíduo.

${ }^{7}$ Como sugerido por Harrison (1994), este valor pode não ser exatamente a verdadeira variação
} 
Tabela 2

Estimação do modelo (14) com participação do trabalho $\left(\alpha_{L}\right)$ variável e deslocamento de produtividade (C3) igual para todos os setores

\begin{tabular}{|c|c|c|c|c|c|}
\hline Setores & $\mathrm{C} 0$ & $\mathrm{C} 1$ & $\mathrm{C} 2$ & C3 & Significância do Mark-Up \\
\hline Transformação de Produtos & 0,046 & 1,897 & $-0,785$ & 0,057 & 0,20 \\
\hline Minerais Não-Metálicos & $(0,023)$ & $(0,690)$ & $(1,071)$ & $(0,010)$ & \\
\hline \multirow[t]{2}{*}{ Metalurgia } & 0,066 & 2,016 & 0,481 & 0,057 & 0,11 \\
\hline & $(0,020)$ & $(0,628)$ & $(0,876)$ & $(0,010)$ & \\
\hline \multirow[t]{2}{*}{ Mecânica } & 0,055 & 0,859 & $-0,098$ & 0,057 & 0,71 \\
\hline & $(0,020)$ & $(0,378)$ & $(0,670)$ & $(0,010)$ & \\
\hline Material Elétrico e de & 0,058 & 1,681 & $-0,040$ & 0,057 & 0,40 \\
\hline Comunicações & $(0,024)$ & $(0,805)$ & $(2,510)$ & $(0,010)$ & \\
\hline \multirow[t]{2}{*}{ Material de Transporte } & 0,024 & 1,783 & $-0,248$ & 0,057 & 0,17 \\
\hline & $(0,023)$ & $(0,563)$ & $(0,706)$ & $(0,010)$ & \\
\hline \multirow[t]{2}{*}{ Papel e Papelão } & 0,042 & 1,022 & $-0,235$ & 0,057 & 0,96 \\
\hline & $(0,023)$ & $(0,450)$ & $(0,594)$ & $(0,010)$ & \\
\hline \multirow[t]{2}{*}{ Borracha } & 0,055 & 2,849 & 0,171 & 0,057 & 0,00 \\
\hline & $(0,020)$ & $(0,581)$ & $(1,401)$ & $(0,010)$ & \\
\hline \multirow[t]{2}{*}{ Química } & 0,066 & 4,552 & 0,036 & 0,057 & 0,05 \\
\hline & $(0,023)$ & $(1,757)$ & $(1,908)$ & $(0,010)$ & \\
\hline Produtos Farmacêuticos e & 0,019 & 1,896 & $-2,050$ & 0,057 & 0,08 \\
\hline Veterinários & $(0,018)$ & $(0,506)$ & $(1,020)$ & $(0,010)$ & \\
\hline \multirow[t]{2}{*}{ Perfumaria, Sabões e Velas } & 0,058 & 1,968 & 0,054 & 0,057 & 0,00 \\
\hline & $(0,019)$ & $(0,245)$ & $(0,837)$ & $(0,010)$ & \\
\hline Produtos de Materiais & 0,048 & 2,335 & 0,831 & 0,057 & 0,01 \\
\hline Plásticos & $(0,021)$ & $(0,477)$ & $(0,683)$ & $(0,010)$ & \\
\hline \multirow{2}{*}{ Têxtil } & 0,067 & 3,385 & 2,783 & 0,057 & 0,00 \\
\hline & $(0,022)$ & $(0,685)$ & $(1,730)$ & $(0,010)$ & \\
\hline Vestuário, Calçados e & 0,051 & 1,341 & 0,238 & 0,057 & 0,09 \\
\hline Artefatos de Tecidos & $(0,021)$ & $(0,197)$ & $(0,357)$ & $(0,010)$ & \\
\hline \multirow[t]{2}{*}{ Alimentícia } & 0,057 & 2,615 & 1,701 & 0,057 & 0,01 \\
\hline & $(0,019)$ & $(0,583)$ & $(1,281)$ & $(0,010)$ & \\
\hline \multirow[t]{2}{*}{ Bebidas } & 0,062 & 1,257 & $-0,376$ & 0,057 & 0,37 \\
\hline & $(0,018)$ & $(0,284)$ & $(0,473)$ & $(0,010)$ & \\
\hline \multirow[t]{2}{*}{ Fumo } & 0,087 & 1,920 & 0,042 & 0,057 & 0,00 \\
\hline & $(0,019)$ & $(0,251)$ & $(0,301)$ & $(0,010)$ & \\
\hline
\end{tabular}

Desvio padrão entre parênteses.

O mark-up do preço sobre o custo marginal, estimado pelo coeficiente $C_{1}$, é significativo para todos os setores da indústria de transformação. O coeficiente estimado é significativamente diferente de um, calculado da forma indicada na nota de rodapé (5), para sete setores (Borracha, Química, Perfumaria, Sabões e Velas, Produtos de Materiais Plásticos, Têxtil, Alimentícia e Fumo) ao nível de significância de cinco por cento, podendo-se incluir mais dois setores (Produtos Farmacêuticos e Veterinários, Vestuário, Calçados e Artefatos de Tecidos) ao nível de nove por cento. Verifica-se altos níveis e grande variação (34\% a 350\%) da

de produtividade, pois ao impor retornos constantes de escala estamos omitindo possíveis ganhos de produtividade oriundos do uso de retornos crescentes de escala se, por exemplo, a tecnologia apresentar retornos crescentes de escala. 
margem de mark-up entre setores. ${ }^{8}$

Neste estágio pode-se notar a relevância do cálculo correto da participação da mão de obra no produto total. Quando utilizamos o valor 0,65, encontramos somente três setores (Perfumaria, Sabões e Velas, Vestuário, Calçados e Artefatos de Tecidos e Fumo) com mark-up diferente de um a cinco por cento de significância. Com participação da mão de obra no produto total igual a 0,55 encontramos quatro setores (os três anteriores e o setor Têxtil) com mark-up diferente de um ao nível de significância de cinco por cento, e finalmente com participação da mão de obra no produto total igual a 0,50 encontramos cinco setores (os quatro anteriores e Produtos de Materiais Plásticos) com mark-up diferente de um ao nível de significância de cinco por cento. Acreditamos, entretanto que os resultados da tabela 2 sejam os mais confiáveis, por não imporem a mesma participação do trabalho em todos os setores e por utilizarem dados de boa qualidade para construir este parâmetro. Os resultados com $\alpha_{L}$ ad hoc e constante por setor, seja ele 0,65 ou 0,50, servem principalmente para chamar a atenção para necessidade de sua estimação ou construção criteriosa em exercícios de medição de produtividade.

O coeficiente que revela alteração no tipo de comportamento de mercado das empresas, $C_{2}$, só é significativo para o setor de Produtos Farmacêuticos e Veterinários ao nível de significância de oito por cento. $\mathrm{O}$ valor negativo da estimativa indica um decréscimo da margem de mark-up para este setor após a abertura. Nos setores restantes não há indicação de alteração significativa no padrão de competição após a liberalização comercial, ao contrário do que se podia esperar.

O deslocamento de produtividade, estimado pelo coeficiente $C_{3}$, para o qual é imposto o mesmo valor entre todos os setores, indica que houve um deslocamento positivo da produtividade de todos os setores. Em outras palavras, este resultado estaria nos dizendo que há um salto na produtividade industrial após a liberalização comercial.

Em resumo, considerando o nível de signicância de nove por cento encontramos nove setores com mark-up significativamente diferente de um, com decréscimo da margem de mark-up somente no setor de produtos Farmacêuticos e Veterinários, e variação positiva de produtividade em todos os setores já que o coeficiente estimado da dummy de 0,057 indica que a produtividade total dos fatores é maior após a abertura. Neste último caso convém lembrar que imputamos valor zero para os anos pré-abertura comercial. Os resultados obtidos nesta seção indicam que o

${ }^{8}$ A estimação pontual para a indústria química, por ser exageradamente alta e muito acima das demais estimativas, exige alguma cautela em sua interpretação. Talvez mais do que alto poder de monopólio ou baixa elasticidade da demanda, este resultado pode estar indicando que os dados deste setor seriam de pior qualidade. O problema é ainda pior na tabela 3. 
poder de mercado é muito sensível ao valor imposto para a participação da mão de obra no produto total.

\subsection{Modelo com deslocamento de produtividade diferente para cada setor}

Neste segundo exercício estimamos o modelo (14) por mínimos quadrados ordinários e variáveis instrumentais, permitindo que cada setor tenha seu próprio salto de produtividade, i.e., o coeficiente $C_{3}$ será diferente entre os setores. Novamente, o teste de Hausman, tabela A.2 do apêndice, não indica a existência de diferença entre os coeficientes estimados por mínimos quadrados ordinários e variáveis instrumentais, quando aplicado para cada equação. As estimações apresentam um padrão semelhante quando comparamos a interseção dos coeficientes significativos estimados, embora nas estimações por variáveis instrumentais tenha se observado uma ligeira redução dos coeficientes estatisticamente significativos. Os resultados da estimação deste modelo, com participações do trabalho no produto total, $\alpha_{L}$, calculadas a partir da matriz insumo-produto, encontram-se descritos na tabela 3 a seguir.

O mark-up do preço sobre o custo marginal, estimado pelo coeficiente $C_{1}$, não é significativo em duas indústrias (Mecânica e Material Elétrico e de Comunicações). Dos setores restantes, este coeficiente é significativamente diferente de um em dez setores (Metalurgia, Material de Transporte, Borracha, Química, Perfumaria, Sabões e Velas, Produtos de Materiais Plásticos, Têxtil, Vestuário, Calçados e Artefatos de Tecido, Alimentícia e Fumo).

A variação do mark-up do preço sobre o custo marginal, estimada pelo coeficiente $C_{2}$, é significativa somente para a indústria Alimentícia. O coeficiente positivo neste caso revela um acréscimo do poder de mercado, o que indica, de maneira contrária a esperada, um comportamento menos competitivo desta indústria. Da mesma forma, a inexistência de evidências significativas de aumento da concorrência nas outras 15 indústrias é um resultado inesperado, mas semelhante ao anterior.

O deslocamento de produtividade, $C_{3}$, indica aumento da taxa de crescimento da produtividade em todos os 16 setores após a abertura comercial, embora o coeficiente estimado somente seja é significativo em sete destes setores (Material de transporte, Papel e papelão, Química, Produtos de materiais plásticos, Têxtil, Vestuário, calçados e artefatos de tecidos e Alimentícia) a cinco por cento. Com seis por cento de significância pode ser incluída a indústria de Borracha e a dez por cento a indústria de Metalurgia. 
Tabela 3

Estimação do modelo (14) com participação do trabalho variável $\left(\alpha_{L}\right)$ e deslocamento de produtividade (C3) diferente para cada setor

\begin{tabular}{|c|c|c|c|c|c|}
\hline Setores & $\mathrm{C} 0$ & C1 & $\mathrm{C} 2$ & C3 & Significância do Mark-Up \\
\hline Transformação de Produtos & 0,037 & 1,727 & $-0,921$ & 0,043 & 0,40 \\
\hline Minerais Não-Metálicos & $(0,036)$ & $(0,855)$ & $(1,127)$ & $(0,044)$ & \\
\hline Metalurgia & $\begin{array}{c}0,063 \\
(0,020)\end{array}$ & $\begin{array}{c}1,985 \\
(0,508)\end{array}$ & $\begin{array}{c}0,480 \\
(0,670)\end{array}$ & $\begin{array}{c}0,051 \\
(0,031)\end{array}$ & 0,05 \\
\hline Mecânica & $\begin{array}{c}0,031 \\
(0,023)\end{array}$ & $\begin{array}{c}0,671 \\
(0,351)\end{array}$ & $\begin{array}{l}-0,053 \\
(0,591)\end{array}$ & $\begin{array}{c}0,001 \\
(0,034)\end{array}$ & 0,35 \\
\hline $\begin{array}{l}\text { Material Elétrico e de } \\
\text { Comunicações }\end{array}$ & $\begin{array}{c}0,044 \\
(0,039)\end{array}$ & $\begin{array}{c}1,356 \\
(1,035)\end{array}$ & $\begin{array}{l}-0,547 \\
(2,570)\end{array}$ & $\begin{array}{c}0,036 \\
(0,047)\end{array}$ & 0,73 \\
\hline Material de Transporte & $\begin{array}{c}0,068 \\
(0,033)\end{array}$ & $\begin{array}{c}2,473 \\
(0,653)\end{array}$ & $\begin{array}{c}0,480 \\
(0,771)\end{array}$ & $\begin{array}{c}0,124 \\
(0,041)\end{array}$ & 0,03 \\
\hline Papel e Papelão & $\begin{array}{c}0,042 \\
(0,017)\end{array}$ & $\begin{array}{c}1,026 \\
(0,275)\end{array}$ & $\begin{array}{l}-0,229 \\
(0,396)\end{array}$ & $\begin{array}{c}0,058 \\
(0,024)\end{array}$ & 0,93 \\
\hline Borracha & $\begin{array}{c}0,062 \\
(0,027)\end{array}$ & $\begin{array}{c}2,951 \\
(0,613)\end{array}$ & $\begin{array}{c}0,296 \\
(1,371)\end{array}$ & $\begin{array}{c}0,070 \\
(0,037)\end{array}$ & 0,00 \\
\hline Química & $\begin{array}{c}0,083 \\
(0,017)\end{array}$ & $\begin{array}{c}5,287 \\
(1,090)\end{array}$ & $\begin{array}{l}1,460 \\
(1,387)\end{array}$ & $\begin{array}{c}0,098 \\
(0,026)\end{array}$ & 0,00 \\
\hline $\begin{array}{l}\text { Produtos Farmacêuticos e } \\
\text { Veterinários }\end{array}$ & $\begin{array}{c}0,011 \\
(0,039)\end{array}$ & $\begin{array}{c}1,845 \\
(0,855)\end{array}$ & $\begin{array}{l}-2,015 \\
(1,702)\end{array}$ & $\begin{array}{c}0,036 \\
(0,059)\end{array}$ & 0,32 \\
\hline Perfumaria, Sabões e Velas & $\begin{array}{c}0,049 \\
(0,030)\end{array}$ & $\begin{array}{c}1,952 \\
(0,325)\end{array}$ & $\begin{array}{c}0,435 \\
(1,293)\end{array}$ & $\begin{array}{c}0,026 \\
(0,056)\end{array}$ & 0,00 \\
\hline $\begin{array}{l}\text { Produtos de Materiais } \\
\text { Plásticos }\end{array}$ & $\begin{array}{c}0,086 \\
(0,042)\end{array}$ & $\begin{array}{c}2,811 \\
(0,745)\end{array}$ & $\begin{array}{l}1,300 \\
(0,990)\end{array}$ & $\begin{array}{c}0,123 \\
(0,055)\end{array}$ & 0,02 \\
\hline Têxtil & $\begin{array}{c}0,081 \\
(0,028)\end{array}$ & $\begin{array}{c}3,599 \\
(0,768)\end{array}$ & $\begin{array}{c}2,276 \\
(1,926)\end{array}$ & $\begin{array}{c}0,094 \\
(0,046)\end{array}$ & 0,00 \\
\hline $\begin{array}{l}\text { Vestuário, Calçados e } \\
\text { Artefatos de Tecidos }\end{array}$ & $\begin{array}{c}0,066 \\
(0,026)\end{array}$ & $\begin{array}{c}1,412 \\
(0,194)\end{array}$ & $\begin{array}{c}0,363 \\
(0,350)\end{array}$ & $\begin{array}{c}0,085 \\
(0,036)\end{array}$ & 0,04 \\
\hline Alimentícia & $\begin{array}{c}0,061 \\
(0,011)\end{array}$ & $\begin{array}{c}2,656 \\
(0,281)\end{array}$ & $\begin{array}{l}1,740 \\
(0,600)\end{array}$ & $\begin{array}{c}0,066 \\
(0,017)\end{array}$ & 0,00 \\
\hline Bebidas & $\begin{array}{c}0,045 \\
(0,029)\end{array}$ & $\begin{array}{l}1,185 \\
(0,350)\end{array}$ & $\begin{array}{c}-0,514 \\
(0,588)\end{array}$ & $\begin{array}{c}0,019 \\
(0,043)\end{array}$ & 0,60 \\
\hline Fumo & $\begin{array}{c}0,071 \\
(0,024)\end{array}$ & $\begin{array}{c}1,857 \\
(0,259)\end{array}$ & $\begin{array}{l}-0,067 \\
(0,320)\end{array}$ & $\begin{array}{c}0,021 \\
(0,037)\end{array}$ & 0,00 \\
\hline
\end{tabular}

Desvio padrão entre parênteses.

Finalmente, o resultado para os coeficiente $C_{0}$ não é significativo para seis setores (Transformação de Produtos Minerais Não-Metálicos, Mecânica, Material Elétrico e de Comunicações, Produtos Farmacêuticos e Veterinários, Perfumaria Sabões e Velas e Bebidas). Como esperado, os coeficientes estimados significativos são todos maiores que zero indicando aumento da produtividade média nestes setores.

Sintetizando, os resultados obtidos nesta seção indicam um crescimento da produtividade média em grande parte dos setores incluídos neste exercício, mostram que existe o indício de poder de mercado em dez setores industriais, que a variação de mark-up só é significativa para uma indústria e, por último, que existe evidência de um deslocamento de produtividade induzido pela abertura em nove 
setores industriais.

\subsection{Modelo sem impor restrição de retornos constantes de escala}

O modelo (16) foi estimado pelo método de mínimos quadrados ordinários e variáveis instrumentais. O resultado do teste de Hausman, tabela A.3 do apêndice, aplicado equação por equação, não rejeita a hipótese nula de igualdade de coeficientes entre as estimativas de todas as equações. Novamente, como nos casos anteriores, as estimações apresentam um padrão bastante semelhante. Diante destes resultados, usaremos para análise a estimação por mínimos quadrados ordinários cujo resultados encontram-se na tabela 4 a seguir.

Nesta estimação não impusemos a restrição de igualdade do coeficiente que mede o salto de produtividade. Novamente, a constante específica de planta é igual a zero porque estamos utilizando dados agregados por setores.

O coeficiente de produtividade média estimado, $C_{0}$, é significativo em cinco setores industriais (Metalurgia, Papel e Papelão, Química, Alimentícia e Fumo) enquanto que o coeficiente de poder de mercado estimado, $C_{1}$, é significativo em seis setores industriais (Metalurgia, Papel e Papelão, Química, Têxtil, Vestuário, Calçados e Artefatos de Tecidos e Fumo), porém não é significativamente diferente de um em nenhum destes setores.

A variação do mark-up do preço sobre o custo marginal, estimada pelo coeficiente $C_{2}$, é significativa somente para o setor de Borracha, revelando um acréscimo do poder de mercado, o que pode indicar como no caso anterior, e de maneira contrária a esperada, um comportamento menos competitivo desta indústria. Moreira (1999), a partir de dados da matriz insumo-produto, também encontra alguns (poucos) setores com elevação de mark-up.

O deslocamento de produtividade, estimado pelo coeficiente $C_{3}$, indica um deslocamento positivo de produtividade em dois setores (Material de Transportes e Química).

O coeficiente de escala, $C_{4}$, apesar de significativo em três setores industriais (Borracha, Produtos de Materiais Plásticos e Têxtil), indica um resultado não esperado e pouco intuitivo pois os coeficientes estimados são menores que um, o que indicaria rendimentos decrescentes de escala. Em Harrison (1994) foram obtidos coeficientes menores que um, implicando em tecnologia caracterizada por retornos de escala decrescente.

O fato dos coeficientes de escala estimados não serem significativos em 13 das 16 indústrias estudadas pode indicar má especificação do modelo, o que explicaria a dissemelhança entre os resultados deste modelo e do anterior, com retornos 
constantes de escala, em relação aos outros coeficientes estimados (e.g., $C_{1}$ diferente de um somente em uma indústria, e mesmo assim a oito por cento). As estimativas do coeficiente de escala, menores que um, merecem um estudo mais detalhado, mas este resultado pode ser causado por políticas especiais do governo para estes setores ou pode ser reflexo da agregação dos dados, ou, de novo, má especificação do modelo. De uma forma geral, estes resultados acabam por nos dar mais confiança no modelo anterior.

Tabela 4

Estimação do modelo (16) com participação do trabalho $\left(\alpha_{L}\right)$ variável e deslocamento de produtividade (C3) diferente para cada setor

\begin{tabular}{|c|c|c|c|c|c|c|}
\hline Setores & $\mathrm{C} 0$ & $\mathrm{C} 1$ & $\mathrm{C} 2$ & C3 & $\mathrm{C} 4$ & $\begin{array}{l}\text { Significância do } \\
\text { Mark-Up }\end{array}$ \\
\hline Transformação de Produtos & 0,022 & 0,718 & $-0,035$ & 0,013 & $-0,409$ & 0,84 \\
\hline Minerais Não-Metálicos & $(0,039)$ & $(1,382)$ & $(1,479)$ & $(0,055)$ & $(0,437)$ & \\
\hline Metalurgia & $\begin{array}{c}0,061 \\
(0,023)\end{array}$ & $\begin{array}{c}1,874 \\
(0,690)\end{array}$ & $\begin{array}{c}0,575 \\
(0,803)\end{array}$ & $\begin{array}{c}0,048 \\
(0,036)\end{array}$ & $\begin{array}{l}-0,078 \\
(0,303)\end{array}$ & 0,21 \\
\hline Mecânica & $\begin{array}{c}0,048 \\
(0,029)\end{array}$ & $\begin{array}{l}1,170 \\
(0,627)\end{array}$ & $\begin{array}{l}-0,241 \\
(0,625)\end{array}$ & $\begin{array}{c}0,023 \\
(0,041)\end{array}$ & $\begin{array}{c}0,234 \\
(0,243)\end{array}$ & 0,79 \\
\hline $\begin{array}{l}\text { Material Elétrico e de } \\
\text { Comunicações }\end{array}$ & $\begin{array}{c}0,032 \\
(0,050)\end{array}$ & $\begin{array}{c}0,847 \\
(1,639)\end{array}$ & $\begin{array}{c}0,232 \\
(3,295)\end{array}$ & $\begin{array}{c}0,026 \\
(0,055)\end{array}$ & $\begin{array}{l}-0,117 \\
(0,280)\end{array}$ & 0,93 \\
\hline Material de Transporte & $\begin{array}{c}0,063 \\
(0,033)\end{array}$ & $\begin{array}{c}1,660 \\
(0,931)\end{array}$ & $\begin{array}{c}0,804 \\
(0,798)\end{array}$ & $\begin{array}{c}0,112 \\
(0,041)\end{array}$ & $\begin{array}{l}-0,292 \\
(0,244)\end{array}$ & 0,48 \\
\hline Papel e Papelão & $\begin{array}{c}0,041 \\
(0,020)\end{array}$ & $\begin{array}{c}0,958 \\
(0,489)\end{array}$ & $\begin{array}{l}-0,246 \\
(0,433)\end{array}$ & $\begin{array}{c}0,054 \\
(0,034)\end{array}$ & $\begin{array}{l}-0,051 \\
(0,296)\end{array}$ & 0,93 \\
\hline Borracha & $\begin{array}{c}0,023 \\
(0,017)\end{array}$ & $\begin{array}{c}0,485 \\
(0,646)\end{array}$ & $\begin{array}{c}1,569 \\
(0,800)\end{array}$ & $\begin{array}{c}0,011 \\
(0,024)\end{array}$ & $\begin{array}{l}-0,715 \\
(0,160)\end{array}$ & 0,43 \\
\hline Química & $\begin{array}{c}0,074 \\
(0,033)\end{array}$ & $\begin{array}{c}4,625 \\
(2,282)\end{array}$ & $\begin{array}{c}2,147 \\
(2,518)\end{array}$ & $\begin{array}{c}0,097 \\
(0,028)\end{array}$ & $\begin{array}{l}-0,204 \\
(0,607)\end{array}$ & 0,11 \\
\hline $\begin{array}{l}\text { Produtos Farmacêuticos e } \\
\text { Veterinários }\end{array}$ & $\begin{array}{c}0,014 \\
(0,039)\end{array}$ & $\begin{array}{c}4,099 \\
(2,650)\end{array}$ & $\begin{array}{l}-1,305 \\
(1,895)\end{array}$ & $\begin{array}{c}0,053 \\
(0,063)\end{array}$ & $\begin{array}{c}0,763 \\
(0,848)\end{array}$ & 0,24 \\
\hline Perfumaria, Sabões e Velas & $\begin{array}{c}0,045 \\
(0,029)\end{array}$ & $\begin{array}{c}1,135 \\
(0,687)\end{array}$ & $\begin{array}{c}0,272 \\
(1,241)\end{array}$ & $\begin{array}{c}0,009 \\
(0,055)\end{array}$ & $\begin{array}{l}-0,420 \\
(0,315)\end{array}$ & 0,84 \\
\hline $\begin{array}{l}\text { Produtos de Materiais } \\
\text { Plásticos }\end{array}$ & $\begin{array}{c}0,023 \\
(0,041)\end{array}$ & $\begin{array}{c}0,207 \\
(1,175)\end{array}$ & $\begin{array}{c}1,305 \\
(0,763)\end{array}$ & $\begin{array}{c}0,031 \\
(0,056)\end{array}$ & $\begin{array}{l}-0,685 \\
(0,270)\end{array}$ & 0,50 \\
\hline Têxtil & $\begin{array}{c}0,039 \\
(0,031)\end{array}$ & $\begin{array}{c}2,251 \\
(0,916)\end{array}$ & $\begin{array}{c}2,204 \\
(1,620)\end{array}$ & $\begin{array}{c}0,041 \\
(0,047)\end{array}$ & $\begin{array}{l}-0,441 \\
(0,213)\end{array}$ & 0,17 \\
\hline $\begin{array}{l}\text { Vestuário, Calçados e } \\
\text { Artefatos de Tecidos }\end{array}$ & $\begin{array}{c}0,033 \\
(0,033)\end{array}$ & $\begin{array}{c}0,998 \\
(0,337)\end{array}$ & $\begin{array}{c}0,364 \\
(0,327)\end{array}$ & $\begin{array}{c}0,064 \\
(0,037)\end{array}$ & $\begin{array}{l}-0,263 \\
(0,180)\end{array}$ & 1,00 \\
\hline Alimentícia & $\begin{array}{c}0,046 \\
(0,015)\end{array}$ & $\begin{array}{c}1,460 \\
(0,831)\end{array}$ & $\begin{array}{c}1,226 \\
(0,652)\end{array}$ & $\begin{array}{c}0,042 \\
(0,022)\end{array}$ & $\begin{array}{l}-0,414 \\
(0,273)\end{array}$ & 0,58 \\
\hline Bebidas & $\begin{array}{c}0,049 \\
(0,036)\end{array}$ & $\begin{array}{c}1,417 \\
(1,194)\end{array}$ & $\begin{array}{l}-0,518 \\
(0,627)\end{array}$ & $\begin{array}{c}0,027 \\
(0,058)\end{array}$ & $\begin{array}{c}0,099 \\
(0,485)\end{array}$ & 0,73 \\
\hline Fumo & $\begin{array}{c}0,070 \\
(0,025)\end{array}$ & $\begin{array}{l}1,569 \\
(0,421)\end{array}$ & $\begin{array}{c}0,038 \\
(0,347)\end{array}$ & $\begin{array}{c}0,022 \\
(0,038)\end{array}$ & $\begin{array}{l}-0,212 \\
(0,243)\end{array}$ & 0,18 \\
\hline
\end{tabular}

Desvio padrão entre parênteses. 


\section{Conclusão}

Contrariamente à pesquisa existente, que visa concentrar-se nas implicações da abertura comercial sobre variações de produtividade da indústria, esta pesquisa amplia o leque de efeitos estudados. Além de estimarmos o poder de mercado, o que possui interesse em si mesmo, estudamos os possíveis efeitos das reformas sobre este poder de mercado, o deslocamento de produtividade induzido e a escala dos diferentes setores da indústria de transformação brasileira.

Os resultados das estimações indicam a existência de um significativo aumento na produtividade industrial na maior parte dos setores estudados. O canal para este aumento de produtividade, aparentemente, não é o aumento da concorrência, já que não há evidência estatística de redução de mark-up. Este talvez o resultado mais surpreendente do artigo, o fato de que o mark-up não se modificar significativamente após a abertura comercial. Os setores estimados como não concorrencial antes da abertura continuaram a ser depois dela. Acesso a insumos importados e uso de novas tecnologias podem ser possíveis canais de aumento de produtividade. Este resultado está em desacordo com Moreira (1999) que constrói diretamente dos dados medidas de mark-up.

Especificações alternativas foram testadas sem muito sucesso. Incluímos diretamente no modelo medidas de proteção comercial tais como tarifa nominal média e taxa de proteção efetiva. A primeira mediria competição no mercado de produto e a segunda, por conter em sua construção tarifa dos insumos utilizados, poderia ser vista com uma proxy do custo dos insumos importados (supostamente de melhor qualidade e mais eficientes). Entretanto, a inclusão destas variáveis no modelo não alteram os resultados das estimações, seja qual for a especificação do modelo. Mais ainda, na grande maioria dos modelos os coeficientes estimados das medidas de proteção não são estatisticamente significativos aos níveis de significância usuais. Se por um lado este resultado está em desacordo com resultados anteriores da literatura, por outro lado a inclusão ad hoc de variáveis de controle não nos dá muitas pistas sobre o efeito esperado destas. 


\section{Referências}

Carvalho, P. G. M. (2000). As causas do aumento da produtividade da indústria brasileira nos anos 90. Tese de Doutorado, Instituto de Economia da Universidade Federal do Rio de Janeiro.

Domowitz, I., Hubbard, R. G., \& Petersen, B. C. (1988). Market structure and cyclical fluctuations in US manufacturing. The Review of Economics and Statistics, 70:55-66.

Ferreira, P. C., Issler, J. V., \& Pessôa, S. (2000). On the nature of income inequality across nations. EPGE-FGV, mimeo.

Ferreira, P. C. \& Rossi Jr., J. L. (2003). New Evidence from Brazil on Trade Liberalization and Productivity Growth. Internacional Economic Review. forthcoming.

Hall, R. E. (1988). The relation between price and marginal cost in U.S. industry. Journal of Political Economy, 96(5):921-947.

Hall, R. E. \& Jones, C. (1999). Why do some countries produce so much more output per worker than others? Quarterly Journal of Economics, 114:83-116.

Harrison, A. E. (1994). Productivity, imperfect competition and trade reform. Journal of International Economics, 36:53-73.

Hay, D. A. (1997). The post 1990 Brazilian trade liberalization and performance of large manufacturing firms: Productivity, market share and profits. Texto para discussão No. 523, Rio de Janeiro, IPEA.

Hidalgo, A. B. (2002). O processo de abertura comercial brasileira e o crescimento da produtividade. Economia Aplicada, 6(1).

Lisboa, M. B., Menezes-Filho, N., \& Schor, A. (2002). Os efeitos da liberalização comercial sobre a produtividade: Competição ou tecnologia. SBE.

Moreira, M. M. (1999). A indústria brasileira nos anos 90. O que já se pode dizer? Em Giambiagi, F. \& Moreira, M. F., editores, A Economia Brasileira nos Anos 90. BNDES.

Muendler, M. (2001). Trade, Technology, and Productivity: A Study of Brazilian Manufacturers, 1986-1998. University of California, Berkeley. Mimeo. 
Rossi, J. L. \& Ferreira, P. C. (1999). Evolução da produtividade industrial brasileira e abertura comercial. Pesquisa e Planejamento Econômico, 29:1-36.

Tybout, J. R., de Melo, J., \& Corbo, V. (1991). The effects of trade reforms on scale and technical efficiency. new evidence from Chile. Journal of International Economics, 31:231-250.

Tybout, J. R. \& Westbrook, M. D. (1995). Trade liberalization and the dimensions of efficiency change in mexican manufacturing industries. Journal of International Economics, 39:53-78.

Young, A. (1995). The tyranny of numbers: Confronting the statistical realities of the East Asian growth experience. Quarterly Journal of Economics, 110:641680 . 


\section{Apendice A}

Tabela A.1

Estimações por mínimos quadrados ordinários e variáveis instrumentais do modelo (14) com deslocamento de produtividade (C3) igual para todos os setores, e resultado do teste de Hausman para estas estimações

\begin{tabular}{|c|c|c|c|c|c|c|c|c|c|}
\hline & \multicolumn{4}{|c|}{ Estimação OLS } & \multicolumn{3}{|c|}{ Estimação IV } & \multirow[b]{2}{*}{ C3 } & \multirow[b]{2}{*}{$\begin{array}{c}\text { Teste } \\
\text { Hausman }\end{array}$} \\
\hline Setores & $\mathrm{CO}$ & $\mathrm{C} 1$ & $\mathrm{C} 2$ & C3 & $\mathrm{CO}$ & $\mathrm{C} 1$ & $\mathrm{C} 2$ & & \\
\hline \multirow{4}{*}{$\begin{array}{l}\text { Transformação de Produtos } \\
\text { Minerais Não-Metálicos } \\
\text { Metalurgia }\end{array}$} & 0,046 & 0,919 & 0,380 & $-0,057$ & 0,040 & 0,809 & 0,542 & $-0,059$ & \multirow[t]{2}{*}{0,26} \\
\hline & $(0,0228)$ & $(0,3346)$ & $(0,5188)$ & $(0,0102)$ & $(0,0292)$ & $(0,4100)$ & $(0,7031)$ & $(0,0183)$ & \\
\hline & 0,066 & 1,269 & $-0,302$ & $-0,057$ & 0,068 & 1,317 & $-0,387$ & $-0,059$ & 0,02 \\
\hline & $(0,0203)$ & $(0,3952)$ & $(0,5515)$ & $(0,0102)$ & $(0,0259)$ & $(0,5171)$ & $(0,8667)$ & $(0,0183)$ & \\
\hline \multirow[t]{2}{*}{ Mecânica } & 0,055 & 0,649 & 0,074 & $-0,057$ & 0,035 & 0,436 & 0,987 & $-0,059$ & \multirow[t]{2}{*}{1,26} \\
\hline & $(0,0197)$ & $(0,2852)$ & $(0,5058)$ & $(0,0102)$ & $(0,0320)$ & $(0,4802)$ & $(1,2148)$ & $(0,0183)$ & \\
\hline \multirow{4}{*}{$\begin{array}{l}\text { Material Elétrico e de } \\
\text { Comunicações } \\
\text { Material de Transporte }\end{array}$} & 0,058 & 0,823 & 0,019 & $-0,057$ & 0,052 & 0,758 & 4,294 & $-0,059$ & \multirow[t]{2}{*}{0,38} \\
\hline & $(0,0244)$ & $(0,3940)$ & $(1,2278)$ & $(0,0102)$ & $(0,0313)$ & $(0,5033)$ & $(7,0733)$ & $(0,0183)$ & \\
\hline & 0,024 & 0,812 & 0,113 & $-0,057$ & 0,046 & 1,015 & $-0,349$ & $-0,059$ & 2,94 \\
\hline & $(0,0226)$ & $(0,2563)$ & $(0,3216)$ & $(0,0102)$ & $(0,0275)$ & $(0,3112)$ & $(0,4365)$ & $(0,0183)$ & \\
\hline \multirow[t]{2}{*}{ Papel e Papelão } & 0,042 & 0,871 & 0,201 & $-0,057$ & 0,042 & 0,921 & 0,042 & $-0,059$ & \multirow[t]{2}{*}{0,18} \\
\hline & $(0,0229)$ & $(0,3832)$ & $(0,5066)$ & $(0,0102)$ & $(0,0276)$ & $(0,5628)$ & $(0,8439)$ & $(0,0183)$ & \\
\hline \multirow[t]{2}{*}{ Borracha } & 0,055 & 1,179 & $-0,071$ & $-0,057$ & 0,041 & 0,935 & 0,972 & $-0,059$ & \multirow[t]{2}{*}{0,98} \\
\hline & $(0,0202)$ & $(0,2403)$ & $(0,5798)$ & $(0,0102)$ & $(0,0292)$ & $(0,3784)$ & $(1,8790)$ & $(0,0183)$ & \\
\hline \multirow[t]{2}{*}{ Química } & 0,066 & 1,527 & $-0,012$ & $-0,057$ & 0,070 & 1,777 & $-0,517$ & $-0,059$ & \multirow[t]{2}{*}{0,29} \\
\hline & $(0,0231)$ & $(0,5894)$ & $(0,6398)$ & $(0,0102)$ & $(0,0257)$ & $(0,8436)$ & $(1,1967)$ & $(0,0183)$ & \\
\hline Produtos Farmacêuticos e & 0,019 & 0,986 & 1,066 & $-0,057$ & 0,007 & 0,812 & 0,734 & $-0,059$ & 5,37 \\
\hline Veterinários & $(0,0181)$ & $(0,2633)$ & $(0,5303)$ & $(0,0102)$ & $(0,0205)$ & $(0,3136)$ & $(0,8290)$ & $(0,0183)$ & \\
\hline \multirow[t]{2}{*}{ Perfumaria, Sabões e Velas } & 0,058 & 1,489 & $-0,041$ & $-0,057$ & 0,061 & 1,440 & $-0,533$ & $-0,059$ & \multirow[t]{2}{*}{2,99} \\
\hline & $(0,0194)$ & $(0,1852)$ & $(0,6337)$ & $(0,0102)$ & $(0,0215)$ & $(0,2067)$ & $(0,7464)$ & $(0,0183)$ & \\
\hline Produtos de Materiais & 0,048 & 1,319 & $-0,469$ & $-0,057$ & 0,059 & 1,278 & $-0,874$ & $-0,059$ & 5,14 \\
\hline Plásticos & $(0,0210)$ & $(0,2693)$ & $(0,3859)$ & $(0,0102)$ & $(0,0411)$ & $(0,6283)$ & $(1,2561)$ & $(0,0183)$ & \\
\hline \multirow[t]{2}{*}{ Têxtil } & 0,067 & 1,542 & $-1,267$ & $-0,057$ & 0,080 & 1,610 & $-2,115$ & $-0,059$ & \multirow[t]{2}{*}{1,83} \\
\hline & $(0,0216)$ & $(0,3119)$ & $(0,7877)$ & $(0,0102)$ & $(0,0277)$ & $(0,3859)$ & $(1,1660)$ & $(0,0183)$ & \\
\hline \multirow{4}{*}{$\begin{array}{l}\text { Vestuário, Calçados e } \\
\text { Artefatos de Tecidos } \\
\text { Alimentícia }\end{array}$} & 0,051 & 1,514 & $-0,269$ & $-0,057$ & 0,055 & 1,547 & $-0,323$ & $-0,059$ & \multirow[t]{2}{*}{0,08} \\
\hline & $(0,0209)$ & $(0,2221)$ & $(0,4033)$ & $(0,0102)$ & $(0,0249)$ & $(0,3215)$ & $(0,7528)$ & $(0,0183)$ & \\
\hline & 0,057 & 1,348 & $-0,877$ & $-0,057$ & 0,059 & 1,347 & $-0,783$ & $-0,059$ & 0,04 \\
\hline & $(0,0186)$ & $(0,3006)$ & $(0,6603)$ & $(0,0102)$ & $(0,0214)$ & $(0,3258)$ & $(0,8690)$ & $(0,0183)$ & \\
\hline \multirow[t]{2}{*}{ Bebidas } & 0,062 & 0,822 & 0,246 & $-0,057$ & 0,054 & 0,819 & 0,388 & $-0,059$ & \multirow[t]{2}{*}{1,39} \\
\hline & $(0,0185)$ & $(0,1855)$ & $(0,3095)$ & $(0,0102)$ & $(0,0208)$ & $(0,2003)$ & $(0,3568)$ & $(0,0183)$ & \\
\hline \multirow[t]{2}{*}{ Fumo } & 0,087 & 1,453 & $-0,032$ & $-0,057$ & 0,077 & 1,112 & 0,510 & $-0,059$ & \multirow[t]{2}{*}{2,35} \\
\hline & $(0,0188)$ & $(0,1898)$ & $(0,2275)$ & $(0,0102)$ & $(0,0213)$ & $(0,2950)$ & $(0,4268)$ & $(0,0183)$ & \\
\hline
\end{tabular}

a) Instrumentos: Taxa de câmbio real externa, horas trabalhadas, razão capital/horas trabalhadas, razão capital/mão de obra empregada e suas respectivas defasagens.

b) O valor do teste é 7,81 . Um valor maior indica a rejeição da hipótese nula de igualdade de estimativa pelos dois métodos. 
Tabela A.2

Estimações por mínimos quadrados ordinários e variáveis instrumentais do modelo (14) com deslocamento de produtividade (C3) diferente para cada setor, e resultado do teste de Hausman para estas estimações

\begin{tabular}{|c|c|c|c|c|c|c|c|c|c|}
\hline & & Estimac & ção OLS & & & timação & & & \\
\hline Setores & $\mathrm{CO}$ & $\mathrm{C} 1$ & $\mathrm{C} 2$ & C3 & $\mathrm{C} 0$ & $\mathrm{C} 1$ & $\mathrm{C} 2$ & C3 & $\begin{array}{c}\text { Teste } \\
\text { Hausman }^{b}\end{array}$ \\
\hline Transformação de Produtos & 0,037 & 0,837 & 0,446 & $-0,043$ & 0,030 & 0,712 & 0,589 & $-0,041$ & 0,40 \\
\hline Minerais Não-Metálicos & $(0,0355)$ & $(0,4145)$ & $(0,5460)$ & $(0,0444)$ & $(0,0414)$ & $(0,4990)$ & $(0,7165)$ & $(0,0556)$ & \\
\hline Metalurgia & $\begin{array}{c}0,063 \\
(0,0200)\end{array}$ & $\begin{array}{c}1,249 \\
(0,3198)\end{array}$ & $\begin{array}{c}-0,302 \\
(0,4218)\end{array}$ & $\begin{array}{c}-0,051 \\
(0,0307)\end{array}$ & $\begin{array}{c}0,091 \\
(0,0403)\end{array}$ & $\begin{array}{c}1,551 \\
(0,5889)\end{array}$ & $\begin{array}{c}-0,608 \\
(0,8781)\end{array}$ & $\begin{array}{c}-0,109 \\
(0,0721)\end{array}$ & 0,80 \\
\hline Mecânica & $\begin{array}{c}0,031 \\
(0,0227)\end{array}$ & $\begin{array}{c}0,507 \\
(0,2653)\end{array}$ & $\begin{array}{c}0,040 \\
(0,4465)\end{array}$ & $\begin{array}{l}-0,001 \\
(0,0341)\end{array}$ & $\begin{array}{c}0,001 \\
(0,0610)\end{array}$ & $\begin{array}{c}0,123 \\
(0,7242)\end{array}$ & $\begin{array}{c}1,165 \\
(1,4796)\end{array}$ & $\begin{array}{c}0,017 \\
(0,1090)\end{array}$ & 0,68 \\
\hline $\begin{array}{l}\text { Material Elétrico e de } \\
\text { Comunicações }\end{array}$ & $\begin{array}{c}0,044 \\
(0,0392)\end{array}$ & $\begin{array}{c}0,663 \\
(0,5064)\end{array}$ & $\begin{array}{c}0,268 \\
(1,2573)\end{array}$ & $\begin{array}{c}-0,036 \\
(0,0469)\end{array}$ & $\begin{array}{c}0,049 \\
(0,0595)\end{array}$ & $\begin{array}{c}0,718 \\
(0,8265)\end{array}$ & $\begin{array}{c}4,047 \\
(8,1095)\end{array}$ & $\begin{array}{l}-0,054 \\
(0,0771)\end{array}$ & 0,27 \\
\hline Material de Transporte & $\begin{array}{c}0,068 \\
(0,0333)\end{array}$ & $\begin{array}{c}1,126 \\
(0,2974)\end{array}$ & $\begin{array}{c}-0,219 \\
(0,3509)\end{array}$ & $\begin{array}{c}-0,124 \\
(0,0410)\end{array}$ & $\begin{array}{c}0,075 \\
(0,0403)\end{array}$ & $\begin{array}{c}1,186 \\
(0,3163)\end{array}$ & $\begin{array}{l}-0,459 \\
(0,3671)\end{array}$ & $\begin{array}{l}-0,113 \\
(0,0651)\end{array}$ & 4,91 \\
\hline Papel e Papelão & $\begin{array}{c}0,042 \\
(0,0169)\end{array}$ & $\begin{array}{c}0,874 \\
(0,2342)\end{array}$ & $\begin{array}{c}0,195 \\
(0,3374)\end{array}$ & $\begin{array}{c}-0,058 \\
(0,0237)\end{array}$ & $\begin{array}{c}0,046 \\
(0,0278)\end{array}$ & $\begin{array}{c}0,965 \\
(0,4134)\end{array}$ & $\begin{array}{c}-0,039 \\
(0,6880)\end{array}$ & $\begin{array}{c}-0,067 \\
(0,0499)\end{array}$ & 0,40 \\
\hline Borracha & $\begin{array}{c}0,062 \\
(0,0271)\end{array}$ & $\begin{array}{c}1,221 \\
(0,2539)\end{array}$ & $\begin{array}{c}-0,123 \\
(0,5673)\end{array}$ & $\begin{array}{c}-0,070 \\
(0,0369)\end{array}$ & $\begin{array}{c}0,049 \\
(0,0506)\end{array}$ & $\begin{array}{c}0,955 \\
(0,4597)\end{array}$ & $\begin{array}{c}1,370 \\
(3,0000)\end{array}$ & $\begin{array}{l}-0,082 \\
(0,1194)\end{array}$ & 0,54 \\
\hline Química & $\begin{array}{c}0,083 \\
(0,0167)\end{array}$ & $\begin{array}{c}1,773 \\
(0,3655)\end{array}$ & $\begin{array}{c}-0,490 \\
(0,4652)\end{array}$ & $\begin{array}{c}-0,098 \\
(0,0260)\end{array}$ & $\begin{array}{c}0,083 \\
(0,0197)\end{array}$ & $\begin{array}{c}1,940 \\
(0,5323)\end{array}$ & $\begin{array}{c}-0,865 \\
(0,7913)\end{array}$ & $\begin{array}{c}-0,094 \\
(0,0334)\end{array}$ & 0,62 \\
\hline $\begin{array}{l}\text { Produtos Farmacêuticos e } \\
\text { Veterinários }\end{array}$ & $\begin{array}{c}0,011 \\
(0,0385)\end{array}$ & $\begin{array}{c}0,960 \\
(0,4446)\end{array}$ & $\begin{array}{c}1,048 \\
(0,8850)\end{array}$ & $\begin{array}{l}-0,036 \\
(0,0594)\end{array}$ & $\begin{array}{c}0,037 \\
(0,0500)\end{array}$ & $\begin{array}{c}0,982 \\
(0,5548)\end{array}$ & $\begin{array}{c}0,302 \\
(1,4594)\end{array}$ & $\begin{array}{c}-0,135 \\
(0,0986)\end{array}$ & 3,45 \\
\hline Perfumaria, Sabões e Velas & $\begin{array}{c}0,049 \\
(0,0299)\end{array}$ & $\begin{array}{c}1,477 \\
(0,2458)\end{array}$ & $\begin{array}{c}-0,329 \\
(0,9791)\end{array}$ & $\begin{array}{c}-0,026 \\
(0,0562)\end{array}$ & $\begin{array}{c}0,041 \\
(0,0409)\end{array}$ & $\begin{array}{c}1,384 \\
(0,2977)\end{array}$ & $\begin{array}{c}-0,803 \\
(1,1051)\end{array}$ & $\begin{array}{c}0,003 \\
(0,0934)\end{array}$ & 1,50 \\
\hline $\begin{array}{l}\text { Produtos de Materiais } \\
\text { Plásticos }\end{array}$ & $\begin{array}{c}0,086 \\
(0,0417)\end{array}$ & $\begin{array}{c}1,587 \\
(0,4204)\end{array}$ & $\begin{array}{c}-0,734 \\
(0,5589)\end{array}$ & $\begin{array}{c}-0,123 \\
(0,0547)\end{array}$ & $\begin{array}{c}0,054 \\
(0,0973)\end{array}$ & $\begin{array}{c}1,222 \\
(1,2829)\end{array}$ & $\begin{array}{c}-0,789 \\
(2,2559)\end{array}$ & $\begin{array}{c}-0,054 \\
(0,0916)\end{array}$ & 2,60 \\
\hline Têxtil & $\begin{array}{c}0,081 \\
(0,0284)\end{array}$ & $\begin{array}{c}1,639 \\
(0,3496)\end{array}$ & $\begin{array}{c}-1,036 \\
(0,8770)\end{array}$ & $\begin{array}{c}-0,094 \\
(0,0462)\end{array}$ & $\begin{array}{c}0,093 \\
(0,0565)\end{array}$ & $\begin{array}{c}1,739 \\
(0,6442)\end{array}$ & $\begin{array}{c}-2,052 \\
(1,3954)\end{array}$ & $\begin{array}{c}-0,091 \\
(0,1152)\end{array}$ & 1,19 \\
\hline $\begin{array}{l}\text { Vestuário, Calçados e } \\
\text { Artefatos de Tecidos }\end{array}$ & $\left(\begin{array}{c}0,066 \\
(0,0257)\end{array}\right.$ & $\begin{array}{c}1,594 \\
(0,2190)\end{array}$ & $\begin{array}{l}-0,410 \\
(0,3950)\end{array}$ & $\begin{array}{l}-0,085 \\
(0,0357)\end{array}$ & $\begin{array}{c}0,047 \\
(0,0487)\end{array}$ & $\begin{array}{c}1,528 \\
(0,3302)\end{array}$ & $\begin{array}{l}-0,361 \\
(0,7651)\end{array}$ & $\begin{array}{l}-0,040 \\
(0,1004)\end{array}$ & 0,37 \\
\hline Alimentícia & $\begin{array}{c}0,061 \\
(0,0114)\end{array}$ & $\begin{array}{c}1,369 \\
(0,1451)\end{array}$ & $\begin{array}{c}-0,897 \\
(0,3095)\end{array}$ & $\begin{array}{c}-0,066 \\
(0,0168)\end{array}$ & $\begin{array}{c}0,063 \\
(0,0148)\end{array}$ & $\begin{array}{c}1,363 \\
(0,1611)\end{array}$ & $\begin{array}{c}-0,863 \\
(0,4658)\end{array}$ & $\begin{array}{c}-0,070 \\
(0,0310)\end{array}$ & 0,15 \\
\hline Bebidas & $\begin{array}{c}0,045 \\
(0,0287)\end{array}$ & $\begin{array}{c}0,775 \\
(0,2286)\end{array}$ & $\begin{array}{c}0,336 \\
(0,3847)\end{array}$ & $\begin{array}{c}-0,019 \\
(0,0433)\end{array}$ & $\begin{array}{c}0,018 \\
(0,0603)\end{array}$ & $\begin{array}{c}0,717 \\
(0,2976)\end{array}$ & $\begin{array}{c}0,590 \\
(0,5464)\end{array}$ & $\begin{array}{c}0,033 \\
(0,1401)\end{array}$ & 0,88 \\
\hline Fumo & $\begin{array}{c}0,071 \\
(0,0242)\end{array}$ & $\begin{array}{c}1,406 \\
(0,1962)\end{array}$ & $\begin{array}{c}0,051 \\
(0,2425)\end{array}$ & $\begin{array}{c}-0,021 \\
(0,0371)\end{array}$ & $\begin{array}{c}0,052 \\
(0,0361)\end{array}$ & $\begin{array}{c}1,126 \\
(0,3506)\end{array}$ & $\begin{array}{c}0,461 \\
(0,5090)\end{array}$ & $\begin{array}{c}0,010 \\
(0,0737)\end{array}$ & 1,42 \\
\hline
\end{tabular}

a) Instrumentos: Taxa de câmbio real externa, horas trabalhadas, razão capital/horas trabalhadas, razão capital/mão de obra empregada e suas respectivas defasagens.

b) O valor do teste é 9,49 . Um valor maior indica a rejeição da hipótese nula de igualdade de estimativa pelos dois métodos. 
Tabela A.3

Estimações por mínimos quadrados ordinários e variáveis instrumentais do modelo (16) com deslocamento de produtividade (C3) igual para todos os setores, e resultado do teste de Hausman para estas estimações

\begin{tabular}{|c|c|c|c|c|c|c|c|c|c|c|c|}
\hline & & Est & timação C & OLS & & & Estima & ação IV & & & \\
\hline Setores & $\mathrm{C} 0$ & C1 & $\mathrm{C} 2$ & C3 & $\mathrm{C} 4$ & $\mathrm{C} 0$ & $\mathrm{C} 1$ & $\mathrm{C} 2$ & $\mathrm{C} 3$ & $\mathrm{C} 4$ & $\begin{array}{c}\text { Teste } \\
\text { Hausman }^{b}\end{array}$ \\
\hline Transformação de Produtos & 0,040 & 0,620 & 0,066 & $-0,042$ & $-0,276$ & 0,046 & 1,524 & 1,270 & $-0,055$ & 0,831 & 1,65 \\
\hline Minerais Nã & $(0,0216)$ & $(0,4153)$ & $(0,6737)$ & $(0,0109)$ & $(0,3420)$ & $(0,0318)$ & $(1,0535)$ & $(1,3559)$ & $(0,0190)$ & $(1,1235)$ & \\
\hline Metalurgia & $\begin{array}{c}0,058 \\
(0,0193)\end{array}$ & $\begin{array}{c}1,146 \\
(0,4383)\end{array}$ & $\begin{array}{c}-0,376 \\
(0,5707)\end{array}$ & $\begin{array}{c}-0,042 \\
(0,0109)\end{array}$ & $\begin{array}{c}-0,097 \\
(0,3204)\end{array}$ & $\begin{array}{c}0,064 \\
(0,0302)\end{array}$ & $\begin{array}{c}1,325 \\
(0,7915)\end{array}$ & $\begin{array}{c}0,310 \\
(1,2373)\end{array}$ & $\begin{array}{c}-0,055 \\
(0,0190)\end{array}$ & $\begin{array}{c}0,309 \\
(0,8844)\end{array}$ & 1,49 \\
\hline Mecânica & $\begin{array}{c}0,058 \\
(0,0200)\end{array}$ & $\begin{array}{c}1,016 \\
(0,4006)\end{array}$ & $\begin{array}{c}0,227 \\
(0,4861)\end{array}$ & $\begin{array}{c}-0,042 \\
(0,0109)\end{array}$ & $\begin{array}{c}0,295 \\
(0,2152)\end{array}$ & $\begin{array}{c}0,045 \\
(0,0412)\end{array}$ & $\begin{array}{c}0,745 \\
(0,7964)\end{array}$ & $\begin{array}{c}1,111 \\
(0,9297)\end{array}$ & $\begin{array}{c}-0,055 \\
(0,0190)\end{array}$ & $\begin{array}{c}0,290 \\
(0,4806)\end{array}$ & 0,55 \\
\hline $\begin{array}{l}\text { Material Elétrico e de } \\
\text { Comunicações }\end{array}$ & $\left(\begin{array}{c}0,045 \\
(0,0252)\end{array}\right.$ & $\begin{array}{c}0,595 \\
(0,5129)\end{array}$ & $\begin{array}{c}-0,147 \\
(1,5418)\end{array}$ & $\begin{array}{c}-0,042 \\
(0,0109)\end{array}$ & $\begin{array}{c}-0,079 \\
(0,2409)\end{array}$ & $\begin{array}{c}0,056 \\
(0,0337)\end{array}$ & $\begin{array}{c}0,766 \\
(0,6522)\end{array}$ & $\begin{array}{c}-1,784 \\
(4,4855)\end{array}$ & $\begin{array}{c}-0,055 \\
(0,0190)\end{array}$ & $\begin{array}{c}-0,029 \\
(0,3957)\end{array}$ & 1,74 \\
\hline Material de Transporte & $\left(\begin{array}{c}0,018 \\
(0,0214)\end{array}\right.$ & $\begin{array}{c}0,321 \\
(0,3630)\end{array}$ & $\begin{array}{c}-0,096 \\
(0,3488)\end{array}$ & $\begin{array}{c}-0,042 \\
(0,0109)\end{array}$ & $\begin{array}{c}-0,394 \\
(0,2514)\end{array}$ & $\begin{array}{c}0,043 \\
(0,0292)\end{array}$ & $\begin{array}{c}1,118 \\
(0,7650)\end{array}$ & $\begin{array}{c}-0,292 \\
(0,5434)\end{array}$ & $\begin{array}{c}-0,055 \\
(0,0190)\end{array}$ & $\begin{array}{c}0,112 \\
(0,6609)\end{array}$ & 0,31 \\
\hline Papel e Papelão & $\left(\begin{array}{c}0,035 \\
(0,0216)\end{array}\right.$ & $\begin{array}{c}0,708 \\
(0,4599)\end{array}$ & $\begin{array}{c}0,286 \\
(0,4908)\end{array}$ & $\begin{array}{c}-0,042 \\
(0,0109)\end{array}$ & $\begin{array}{c}-0,118 \\
(0,3724)\end{array}$ & $\begin{array}{c}0,042 \\
(0,0291)\end{array}$ & $\begin{array}{c}1,262 \\
(0,9269)\end{array}$ & $\begin{array}{c}0,203 \\
(1,0106)\end{array}$ & $\begin{array}{c}-0,055 \\
(0,0190)\end{array}$ & $\begin{array}{c}0,419 \\
(1,0559)\end{array}$ & 2,42 \\
\hline Borracha & $\left(\begin{array}{c}0,041 \\
(0,0193)\end{array}\right.$ & $\begin{array}{c}0,430 \\
(0,3675)\end{array}$ & $\begin{array}{c}-0,650 \\
(0,5962)\end{array}$ & $\begin{array}{c}-0,042 \\
(0,0109)\end{array}$ & $\begin{array}{c}-0,602 \\
(0,2442)\end{array}$ & $\begin{array}{c}0,040 \\
(0,0286)\end{array}$ & $\begin{array}{c}0,271 \\
(0,5905)\end{array}$ & $\begin{array}{c}-0,507 \\
(1,6712)\end{array}$ & $\begin{array}{c}-0,055 \\
(0,0190)\end{array}$ & $\begin{array}{c}-0,787 \\
(0,5266)\end{array}$ & 2,63 \\
\hline Química & $\begin{array}{c}0,043 \\
(0,0450)\end{array}$ & $\begin{array}{c}1,006 \\
(1,1136)\end{array}$ & $\begin{array}{c}-0,352 \\
(1,2827)\end{array}$ & $\begin{array}{c}-0,042 \\
(0,0109)\end{array}$ & $\begin{array}{c}-0,416 \\
(0,9297)\end{array}$ & $\begin{array}{c}0,094 \\
(0,0990)\end{array}$ & $\begin{array}{c}2,400 \\
(2,4202)\end{array}$ & $\begin{array}{c}0,262 \\
(2,9159)\end{array}$ & $\begin{array}{c}-0,055 \\
(0,0190)\end{array}$ & $\begin{array}{c}0,643 \\
(2,3413)\end{array}$ & 0,64 \\
\hline $\begin{array}{l}\text { Produtos Farmacêuticos e } \\
\text { Veterinários }\end{array}$ & $\left(\begin{array}{c}0,010 \\
(0,0171)\end{array}\right.$ & $\begin{array}{c}2,048 \\
(0,7216)\end{array}$ & $\begin{array}{c}0,691 \\
(0,5431)\end{array}$ & $\begin{array}{c}-0,042 \\
(0,0109)\end{array}$ & $\begin{array}{c}0,717 \\
(0,4490)\end{array}$ & $\begin{array}{c}0,006 \\
(0,0216)\end{array}$ & $\begin{array}{c}0,469 \\
(2,2898)\end{array}$ & $\begin{array}{c}0,510 \\
(0,8524)\end{array}$ & $\begin{array}{c}-0,055 \\
(0,0190)\end{array}$ & $\begin{array}{c}-0,278 \\
(1,5234)\end{array}$ & 0,40 \\
\hline Perfumaria, Sabões e Velas & {$\left[\begin{array}{c}0,054 \\
(0,0181)\end{array}\right.$} & $\begin{array}{c}0,938 \\
(0,3726)\end{array}$ & $\begin{array}{c}0,075 \\
(0,6105)\end{array}$ & $\begin{array}{c}-0,042 \\
(0,0109)\end{array}$ & $\begin{array}{c}-0,375 \\
(0,2268)\end{array}$ & $\begin{array}{c}0,057 \\
(0,0229)\end{array}$ & $\begin{array}{c}0,887 \\
(0,6174)\end{array}$ & $\begin{array}{c}-0,344 \\
(0,8071)\end{array}$ & $\begin{array}{c}-0,055 \\
(0,0190)\end{array}$ & $\begin{array}{c}-0,425 \\
(0,4302)\end{array}$ & 1,07 \\
\hline $\begin{array}{l}\text { Produtos de Materiais } \\
\text { Plásticos }\end{array}$ & $\left(\begin{array}{c}0,030 \\
(0,0201)\end{array}\right.$ & $\begin{array}{c}0,223 \\
(0,3977)\end{array}$ & $\begin{array}{c}-0,763 \\
(0,3723)\end{array}$ & $\begin{array}{c}-0,042 \\
(0,0109)\end{array}$ & $\begin{array}{c}-0,648 \\
(0,1876)\end{array}$ & $\begin{array}{c}0,027 \\
(0,0319)\end{array}$ & $\begin{array}{c}0,810 \\
(0,6966)\end{array}$ & $\begin{array}{c}0,362 \\
(0,8364)\end{array}$ & $\begin{array}{c}-0,055 \\
(0,0190)\end{array}$ & $\begin{array}{c}0,074 \\
(0,4468)\end{array}$ & 1,51 \\
\hline Têxtil & $\left(\begin{array}{c}0,040 \\
(0,0225)\end{array}\right.$ & $\begin{array}{c}1,031 \\
(0,3570)\end{array}$ & $\begin{array}{c}-0,999 \\
(0,7488)\end{array}$ & $\begin{array}{c}-0,042 \\
(0,0109)\end{array}$ & $\begin{array}{c}-0,439 \\
(0,1883)\end{array}$ & $\begin{array}{c}0,022 \\
(0,0385)\end{array}$ & $\begin{array}{c}0,776 \\
(0,5641)\end{array}$ & $\begin{array}{c}-0,628 \\
(1,1670)\end{array}$ & $\begin{array}{c}-0,055 \\
(0,0190)\end{array}$ & $\begin{array}{c}-0,642 \\
(0,3699)\end{array}$ & 2,33 \\
\hline $\begin{array}{l}\text { Vestuário, Calçados e } \\
\text { Artefatos de Tecidos }\end{array}$ & $\left(\begin{array}{c}0,019 \\
(0,0253)\end{array}\right.$ & $\begin{array}{c}1,000 \\
(0,3588)\end{array}$ & $\begin{array}{c}-0,322 \\
(0,3834)\end{array}$ & $\begin{array}{c}-0,042 \\
(0,0109)\end{array}$ & $\begin{array}{c}-0,306 \\
(0,1876)\end{array}$ & $\begin{array}{c}-0,015 \\
(0,0429)\end{array}$ & $\begin{array}{c}0,364 \\
(0,6640)\end{array}$ & $\begin{array}{c}-0,088 \\
(0,6200)\end{array}$ & $\begin{array}{c}-0,055 \\
(0,0190)\end{array}$ & $\begin{array}{c}-0,795 \\
(0,3994)\end{array}$ & 0,77 \\
\hline Alimentícia & $\left(\begin{array}{c}0,046 \\
(0,0183)\end{array}\right.$ & $\begin{array}{c}0,757 \\
(0,6446)\end{array}$ & $\begin{array}{c}-0,634 \\
(0,6539)\end{array}$ & $\begin{array}{c}-0,042 \\
(0,0109)\end{array}$ & $\begin{array}{c}-0,411 \\
(0,4251)\end{array}$ & $\begin{array}{c}0,049 \\
(0,0263)\end{array}$ & $\begin{array}{c}0,718 \\
(1,0356)\end{array}$ & $\begin{array}{c}-0,757 \\
(0,9164)\end{array}$ & $\begin{array}{c}-0,055 \\
(0,0190)\end{array}$ & $\begin{array}{c}-0,474 \\
(0,7230)\end{array}$ & 3,80 \\
\hline Bebidas & $\begin{array}{c}0,056 \\
(0,0175)\end{array}$ & $\begin{array}{c}1,059 \\
(0,4471)\end{array}$ & $\begin{array}{c}0,318 \\
(0,2935)\end{array}$ & $\begin{array}{c}-0,042 \\
(0,0109)\end{array}$ & $\begin{array}{c}0,178 \\
(0,2849)\end{array}$ & $\begin{array}{c}0,053 \\
(0,0237)\end{array}$ & $\begin{array}{c}0,974 \\
(0,9878)\end{array}$ & $\begin{array}{c}0,361 \\
(0,3753)\end{array}$ & $\begin{array}{c}-0,055 \\
(0,0190)\end{array}$ & $\begin{array}{c}0,108 \\
(0,6729)\end{array}$ & 4,22 \\
\hline Fumo & $\begin{array}{c}0,079 \\
(0,0178)\end{array}$ & $\begin{array}{c}1,210 \\
(0,2895) \\
\end{array}$ & $\begin{array}{c}-0,077 \\
(0,2272) \\
\end{array}$ & $\begin{array}{c}-0,042 \\
(0,0109) \\
\end{array}$ & $\begin{array}{c}-0,217 \\
(0,2218)\end{array}$ & $\begin{array}{c}0,081 \\
(0,0225) \\
\end{array}$ & $\begin{array}{c}1,319 \\
(0,3811) \\
\end{array}$ & $\begin{array}{c}-0,090 \\
(0,2940) \\
\end{array}$ & $\begin{array}{c}-0,055 \\
(0,0190) \\
\end{array}$ & $\begin{array}{c}-0,135 \\
(0,3102) \\
\end{array}$ & 1,35 \\
\hline
\end{tabular}

